\title{
Elucidating the Mechanism of Excited State Bond Homolysis in Nickel-Bipyridine Photoredox Catalysts
}

\author{
David A. Cagan ${ }^{\mathrm{a}}$, Daniel Bímª Breno Silva ${ }^{\mathrm{a}, \mathrm{b}}$, Nathanael P. Kazmierczak ${ }^{\mathrm{a}}$, Brendon J. \\ McNicholas ${ }^{\mathrm{a}}$, and Ryan G. Hadt ${ }^{\mathrm{a}, *}$
}

${ }^{a}$ Division of Chemistry and Chemical Engineering, Arthur Amos Noyes Laboratory of Chemical Physics, California Institute of Technology, Pasadena, California 91125, United States

${ }^{b}$ Department of Chemistry and Biochemistry, Suffolk University, Boston, Massachusetts 02108, United States

*Corresponding Author: rghadt@ecaltech.edu

\begin{abstract}
Ni 2,2'-bipyridine (bpy) complexes are commonly employed photoredox catalysts of bondforming reactions in organic chemistry. However, the mechanisms by which they operate are still under investigation. One potential mode of catalysis is via entry into $\mathrm{Ni}(\mathrm{I}) / \mathrm{Ni}(\mathrm{III})$ cycles, which can be made possible by light-induced, excited state $\mathrm{Ni}(\mathrm{II})-\mathrm{C}$ bond homolysis. Here we report experimental and computational analyses of a library of $\mathrm{Ni}(\mathrm{II})$-bpy aryl halide complexes, $\mathrm{Ni}\left({ }^{\mathrm{R}}\right.$ bpy $)\left({ }^{\mathrm{R}} \mathrm{Ph}\right) \mathrm{Cl}\left(\mathrm{R}=\mathrm{MeO}, \mathrm{t}-\mathrm{Bu}, \mathrm{H}, \mathrm{MeOOC} ; \mathrm{R}^{\prime}=\mathrm{CH}_{3}, \mathrm{H}, \mathrm{OMe}, \mathrm{F}, \mathrm{CF}_{3}\right)$, to illuminate the mechanism of excited state bond homolysis. At given excitation wavelengths, photochemical homolysis rates span two orders of magnitude across these structures and correlate linearly with Hammett parameters of both bpy and aryl ligands, reflecting structural control over key metal-to-
\end{abstract}


ligand charge transfer (MLCT) and ligand-to-metal charge transfer (LMCT) excited state potential energy surfaces (PESs). Temperature- and wavelength-dependent investigations reveal moderate excited state barriers $\left(\Delta \mathrm{H}^{\ddagger} \sim 4 \mathrm{kcal} \mathrm{mol}^{-1}\right)$ and a minimum energy excitation threshold $(\sim 55 \mathrm{kcal}$ $\mathrm{mol}^{-1}, 525 \mathrm{~nm}$ ), respectively. Correlations to electronic structure calculations further support a mechanism in which repulsive triplet excited state PESs featuring a critical aryl-to-Ni LMCT lead to bond rupture. Structural control over excited state PESs provides a rational approach to utilize photonic energy and leverage excited state bond homolysis processes in synthetic chemistry. 


\section{Introduction}

\subsection{Ni(II)-bpy Photoredox Catalysis.}

Merging thermal catalysis with photochemistry (i.e., photoredox catalysis) has had a profound influence within organic chemistry, including coupling reactions forging $\mathrm{sp}^{2}-\mathrm{sp}^{3}$ and $\mathrm{sp}^{3}-\mathrm{sp}^{3} \mathrm{C}-\mathrm{C}$ or $\mathrm{C}-\mathrm{X}$ bonds and their applications to medicinal chemistry. ${ }^{1-9}$ By leveraging photonic energy to drive key catalytic processes and utilizing earth-abundant transition metals, photoredox catalysis provides an attractive and sustainable means to replace precious metal catalysts. ${ }^{10-14}$ The disparate electron transfer properties of first row transition metal catalysts can also provide pathways to new reactive intermediates and/or excited state pathways that can unlock new mechanistic possibilities for drug synthesis and discovery. However, while methodological studies have demonstrated the power of photoredox approaches in achieving bond-forming reactivity, the mechanisms that underlie these processes are largely unknown. Recent research has taken key steps towards this goal. $4,5,15,16$

In photoredox catalysis, reactive molecular excited states can be generated photochemically through photosensitized energy transfer ${ }^{17-20}$ or direct excitation. ${ }^{16,21,22}$ In either case, the ensuing transition metal photophysics will strongly influence the overall catalytic efficacy by directing the photonic energy to specific pathways, only some of which may be productive to the target reaction. This motivates detailed studies of the excited state potential energy surfaces (PESs) that govern the important photophysics underlying photoredox catalysis.

Being catalytically active via photosensitization or direct excitation, $\mathrm{Ni}(\mathrm{II})$ complexes featuring the bidentate 2,2'-bipyridine (bpy) ligand have received a great deal of attention due to their many applications in photoredox catalysis. For example, MacMillan et al. demonstrated a photosensitized, energy transfer mediated approach to enable Ni(II)-bpy catalyzed coupling of 
aryl halides with carboxylic acids. ${ }^{17}$ In particular, an Ir(III) photosensitizer enabled triplet energy transfer to a ground state $\mathrm{Ni}(\mathrm{II})$-bpy aryl acetate complex (formed in situ from a $\mathrm{Ni}(\mathrm{II})$-bpy aryl halide). Energy transfer from the $\operatorname{Ir}(\mathrm{III})$ complex generates a long-lived triplet excited state of the Ni(II)-bpy complex, which can subsequently undergo reductive elimination of the aryl and acetate ligands, forming a new $\mathrm{C}-\mathrm{O}$ bond (Figure $1 \mathrm{~A}$, top). ${ }^{23}$ The mechanism of this photosensitized, energy transfer-mediated reaction is still being investigated. However, ab initio calculations have suggested a triplet metal-to-ligand charge transfer $\left({ }^{3} \mathrm{MLCT}\right)$ state may be active for excited state $\mathrm{C}-\mathrm{O}$ bond formation. ${ }^{24}$ Furthermore, chemical oxidation of the ground state Ni(II)-bpy complex also facilitates reductive elimination. ${ }^{23}$ These ground and excited state pathways are consistent with earlier research from the Hillhouse group demonstrating ground state chemical oxidation of $\mathrm{Ni}$ (II) complexes to $\mathrm{Ni}(\mathrm{III})$ can trigger reductive elimination and the formation of new $\mathrm{C}-\mathrm{X}$ bonds. ${ }^{25,26}$

In addition to energy transfer pathways, photocatalytic cross couplings can also be driven by direct excitation and can circumvent the need for external photosensitizers, which often contain precious metals. For example, irradiation of the $\mathrm{Ni}(\mathrm{II})$-bpy aryl halide complex in the presence of ancillary ligands enables the downstream formation of new $\mathrm{C}-\mathrm{O}$ bonds (Figure $1 \mathrm{~A}$, bottom). ${ }^{21,22}$ Previous research has noted that direct excitation of the Ni(II)-bpy complex homolytically cleaves the $\mathrm{Ni}(\mathrm{II})-\mathrm{C}($ aryl) bond, generating aryl radicals and a formal $\mathrm{Ni}(\mathrm{I})$ species. This reduced $\mathrm{Ni}$ species may allow access to catalytically active $\mathrm{Ni}(\mathrm{I}) / \mathrm{Ni}(\mathrm{III})$ cycles. ${ }^{16,21,22}$ While the use of lightinduced homolysis to generate reactive Ni species has broad implications for photoredox catalysis, the precise mechanism of this critical bond rupture step is not yet well understood and is the main subject of this study. 


\section{A}

Photosensitized Energy Transfer for C-O Bond Formation (MacMillan, 2017; Scholes, 2020)<smiles>[R]ONC(C)=O</smiles>
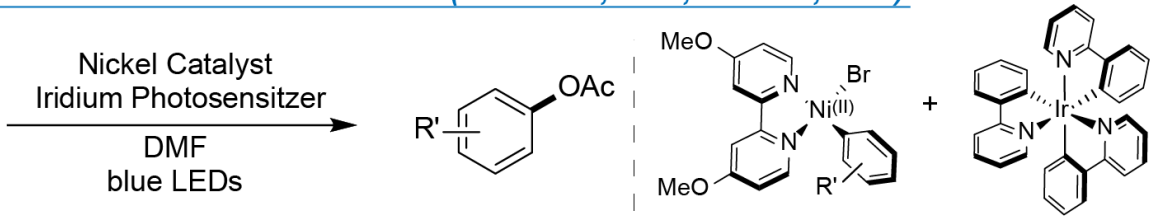

Direct Excitation for C-O Bond Formation (Doyle, 2018; Xue, 2020)

$\mathrm{R}^{\prime} \frac{1}{\mathrm{~L}}+\mathrm{n}^{\mathrm{BuOH}}$

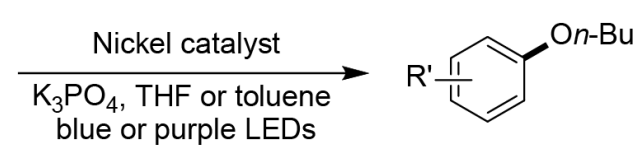

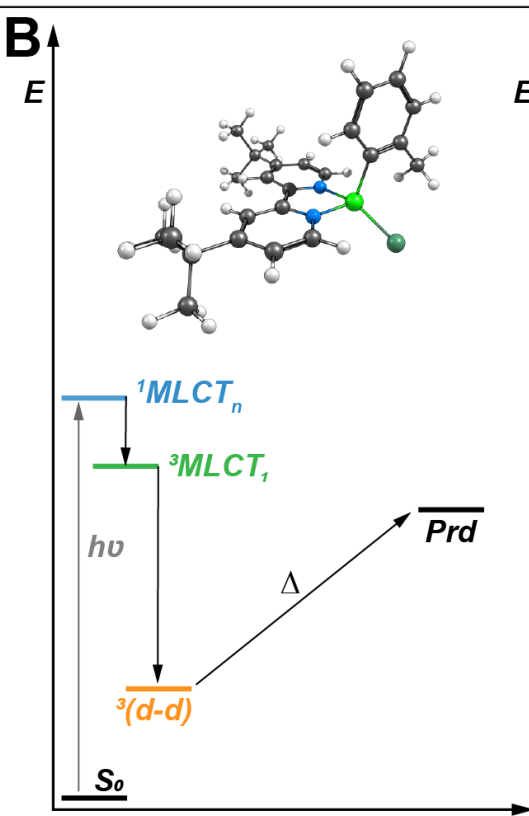

Ni-C Bond Distance $(\AA)$

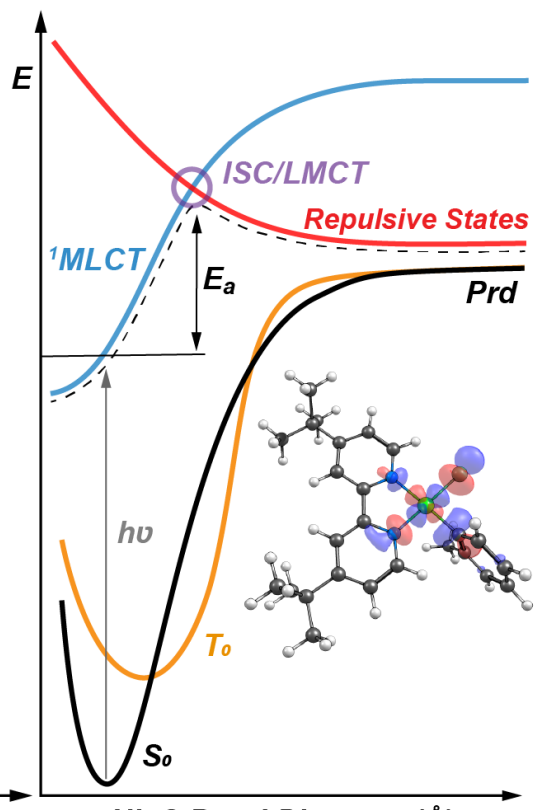

Ni-C Bond Distance (A)

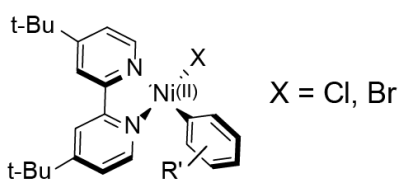

C Experimental and Theoretical Desciption of Ni-C Bond Homolysis

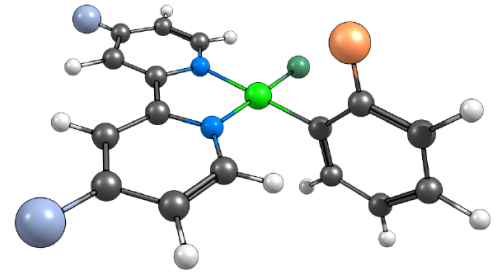

$\mathrm{R}=\mathrm{OMe}, \mathrm{t}-\mathrm{Bu}, \mathrm{H}, \mathrm{MeOOC}$

$\mathrm{R}^{\prime}=\mathrm{CH}_{3}, \mathrm{H}, \mathrm{OMe}, \mathrm{F}, \mathrm{CF}_{3}$

- Photolysis rates, trends, implications

- Excited state barriers and minimum energy threshold

- Structural control over excited state PESs

- One-photon, two-electron repulsive PES: $\left[d\left(x^{2}-y^{2}\right) / C\left(s p^{2}\right)\right]^{1},[d(y z)]^{1} \rightarrow$ $\left[\pi^{*}\right]^{1},\left[d\left(x^{2}-y^{2}\right) / C\left(s p^{2}\right)^{*}\right]^{1}$

Figure 1. (A) Two possible photocatalytic approaches to $\mathrm{Ni}(\mathrm{II})-\mathrm{bpy}$ mediated $\mathrm{C}-\mathrm{O}$ bond formation. (B) Left: Energy diagram showing the direct excitation mechanistic pathway proposed in Reference 16 . The structure of the tetrahedral triplet ligand field excited state ${ }^{3}(d-d)$ is shown. Right: PESs as described in Reference 27 with ab initio calculations showing the ${ }^{3}$ LMCT-based repulsive surface (in red) responsible for $\mathrm{Ni}-\mathrm{C}$ bond homolysis. The antibonding $\mathrm{d}\left(\mathrm{x}^{2}-\mathrm{y}^{2}\right) / \mathrm{C}\left(\mathrm{sp}^{2}\right)^{*}$ orbital is depicted. (C) Summary of this research.

\subsection{Mechanistic Hypotheses for Excited State Ni(II)-C Bond Homolysis.}


There are two proposed excited state $\mathrm{Ni}(\mathrm{II})-\mathrm{C}$ bond homolysis mechanisms in $\mathrm{Ni(II)-bpy} \mathrm{aryl}$ halide complexes. Using a combination of transient optical and IR spectroscopies, Doyle et al. demonstrated that excitation of $\mathrm{Ni}(\mathrm{II})$-bpy singlet metal-to-ligand charge transfer ( $\left.{ }^{1} \mathrm{MLCT}\right)\left(\lambda_{\text {pump }}\right.$ $=530 \mathrm{~nm})$ resulted in the formation of triplet $\mathrm{Ni}(\mathrm{II})$ ligand field excited states $\left({ }^{3}(\mathrm{~d}-\mathrm{d})\right) .{ }^{16}$ Intersystem crossing occurs in $\sim 5-10 \mathrm{ps}$, and the ${ }^{3}(\mathrm{~d}-\mathrm{d})$ state has a lifetime of $\sim 4 \mathrm{~ns}$. Subsequent correlation to density functional theory (DFT) calculations led to the proposal that $\mathrm{Ni(II)-C}$ homolysis occurs thermally from this photochemically formed $\mathrm{Ni}(\mathrm{II}){ }^{3}(\mathrm{~d}-\mathrm{d})$ state (Figure 1B), which features a tetrahedral coordination geometry and a weakened $\mathrm{Ni}(\mathrm{II})-\mathrm{C}$ bond. With DFT, the calculated homolytic bond dissociation energy (BDE) is $\sim 25 \mathrm{kcal} \mathrm{mol}^{-1}$. However, no direct experimental evidence was provided to demonstrate homolysis from the ${ }^{3}(d-d)$ state.

Ab initio multiconfigurational/multireference calculations suggested an alternative mechanism of excited state $\mathrm{Ni}(\mathrm{II})-\mathrm{C}$ bond homolysis that is also consistent with the experimental data provided by Doyle et al. (Figure 1B). ${ }^{27}$ This approach yielded larger homolytic BDEs ( $90 \mathrm{kcal}$ $\mathrm{mol}^{-1}$ from the $\mathrm{S}=0$ geometry, $\sim 70 \mathrm{kcal} \mathrm{mol}^{-1}$ from $\mathrm{S}=1$ geometry) than DFT and highlighted a putative one-photon, two-electron process leading to $\mathrm{Ni}(\mathrm{II})-\mathrm{C}$ bond homolysis. In this mechanism, initial excitation of the $\mathrm{S}=0$ complex forms a ${ }^{1} \mathrm{MLCT}$ state (Ni(II)-to-bpy). From this PES (blue curve in Figure 1B), a ligand-to-metal (aryl-to-Ni(III)) charge transfer (LMCT) PES can be accessed. Critically, this LMCT results in the population of the antibonding $\mathrm{d}\left(\mathrm{x}^{2}-\mathrm{y}^{2}\right) / \mathrm{C}\left(\mathrm{sp}^{2}\right)^{*}$ orbital (Figure 1B, right), which reduces the bond order and results in a repulsive triplet PES, leading to homolytic bond rupture (red curve in Figure 1B, right). ${ }^{27}$ Notably, the energy difference between the MLCT/repulsive triplet crossing point (purple circle Figure 1B, right) and the Frank-Condon point of the MLCT state constitutes the energy barrier $\left(E_{a}\right)$ for bond rupture. Thus, it was reasoned that structural and electronic control over these excited state PESs will result in 
variable rates of excited state $\mathrm{Ni}(\mathrm{II})-\mathrm{C}$ bond homolysis, but new experimental data are required to further elucidate the overall mechanism.

Here we set out to experimentally probe the roles of the excited state PESs by leveraging temperature- and wavelength-dependent photolyses coupled with a range of systematic geometric and electronic structure perturbations across a matrix of Ni(II)-bpy aryl halide complexes (Figure 2). As described above, it was hypothesized that variations in the electron donating/withdrawing nature of the bpy and aryl ligands would allow for direct tuning of the key MLCT/LMCT PESs, the barrier for photolysis, and, consequently, the observed rate of excited state $\mathrm{Ni}(\mathrm{II})-\mathrm{C}$ bond homolysis. Indeed, we demonstrate a direct correlation between experimental rates at given excitation wavelengths and the energies of both of these excited state PESs. Furthermore, we provide the first experimental measure of the excited state energetic barrier for homolysis in $\mathrm{Ni}(\mathrm{II})$-bpy aryl halide complexes utilized as photoredox catalysts. Homolysis rates are wavelength-dependent and have demonstrated a minimum energy threshold for photochemical activation. Coupled to extensive computational analyses, these data provide the first experimental evidence implicating high energy, repulsive aryl-to-Ni LMCT PESs as being vital to homolytically cleaving the $\mathrm{Ni}(\mathrm{II})-\mathrm{C}$ bond, a critical process in photocatalytic $\mathrm{C}-\mathrm{X}$ cross coupling catalysis. Beyond fundamental interest, demonstrating structural and electronic control over the key PESs in photoredox catalysis will, for example, allow chemists to tune the rates of formation of novel reactive intermediates and guide the discovery of new photon-driven organic methodological approaches to coupling reactions. 


\section{Results and Analysis}

\subsection{Experimental Studies.}

In Sections 2.1.1-2.1.5, we detail the syntheses and spectroscopic/photochemical characterizations of a matrix of $\mathrm{Ni}(\mathrm{II})$-bpy aryl halide complexes (Figure 2). We demonstrate direct correlations between ligand-based electronic perturbations, observable MLCT transition energies, and rates of excited state bond homolysis. Temperature- and wavelength-dependent studies provide experimental barriers and energetic thresholds for excited state $\mathrm{Ni}(\mathrm{II})-\mathrm{C}$ bond homolysis, respectively.

\subsubsection{Synthetic Approach.}

To probe the mechanism of excited state Ni(II)-C bond homolysis, we targeted the matrix of $\mathrm{Ni}(\mathrm{II})\left({ }^{\mathrm{R}} \mathrm{bpy}\right)\left({ }^{\mathrm{R}} \mathrm{Ph}\right) \mathrm{Cl}$ complexes $\left(\mathrm{R}=\mathrm{CH}_{3} \mathrm{O}, \mathrm{t}-\mathrm{Bu}, \mathrm{H}, \mathrm{CH}_{3} \mathrm{OOC} ; \mathrm{R}^{\prime}=\right.$ ortho- $\mathrm{CH}_{3}, \mathrm{H}, \mathrm{CH}_{3} \mathrm{O}, \mathrm{F}$, $\mathrm{CF}_{3}$ ), 1A-5D, shown in Figure 2. Two primary synthetic approaches were utilized: 1) oxidative addition and 2) ligand substitution (Scheme S1). In the former, bis-(1,5-cyclooctadiene) nickel(0) was pre-stirred with a given bpy ligand; subsequent reaction with the specific aryl halide resulted in the target complex. The latter method called for either bis(triphenylphosphino)(2methylphenyl)chloronickel(II) or the independent preparation of a pre-catalyst complex, $\mathrm{Ni}(\mathrm{TMEDA})\left({ }^{\mathrm{R}} \mathrm{Ph}\right) \mathrm{Cl}, \mathrm{R}^{\prime}=\mathrm{CH}_{3}$ or $\mathrm{CF}_{3}$, TMEDA $=N, N, N^{\prime}, N^{\prime}$-tetramethyl ethylenediamine. ${ }^{28}$ These TMEDA compounds afforded a more labile ligand that could be substituted by bpy. ${ }^{29}$ The pre-catalyst complexes themselves were prepared by oxidative addition. Ligand substitution was used in cases where oxidative addition proved slow, yielded inconsistent results, or would not produce the desired product. Full synthetic details for both previously prepared ${ }^{16}$ and novel compounds are available in Supporting Information Section S1.3. 


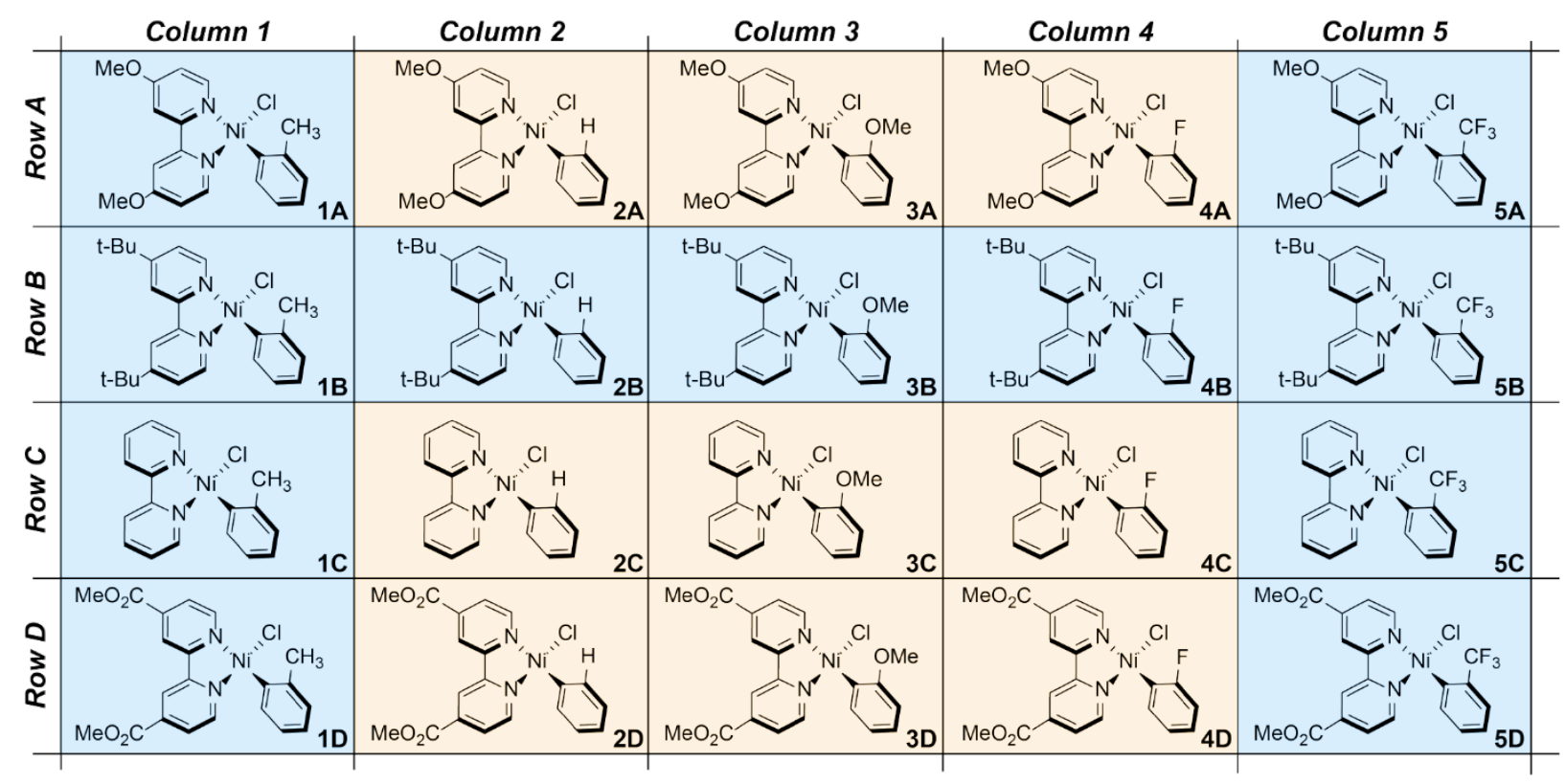

Figure 2. Matrix of $\mathrm{Ni}\left({ }^{\mathrm{R}} \mathrm{bpy}\right)\left({ }^{\mathrm{R}} \mathrm{Ph}\right) \mathrm{Cl}\left(\mathrm{R}=\mathrm{MeO}, \mathrm{t}-\mathrm{Bu}, \mathrm{H}\right.$, and $\mathrm{MeOOC} ; \mathrm{R}^{\prime}=$ ortho- $\mathrm{CH}_{3}, \mathrm{H}, \mathrm{OMe}$, $\mathrm{F}$, and $\mathrm{CF}_{3}$ ) complexes examined in this study. The bpy ligand varies down a column, while the aryl ligand varies across a row. Complexes shaded in blue were synthesized and examined both experimentally and computationally, while those in orange were examined only computationally.

\subsubsection{Steady-state UV-vis Spectroscopy.}

The steady-state UV-vis spectra of the Ni(II)-bpy aryl halide series in tetrahydrofuran (THF) are given in Figure 3A. Molar absorptivity plots in both THF and toluene are also given in Figures S8S10 and are consistent with previous spectral assignments of dominantly MLCT intensity across the UV-vis range. The spectral assignments are discussed further in Section 2.2.1 and given explicitly in Table S8. It is also noted that the MLCT transition energies are generally solvatochromic, with transition energies being lower in toluene relative to THF (Figures S5-S6).

Increasing the electron withdrawing effect of the bpy substituents (proceeding down the columns in Figure 2) generally decreases the energies of the ${ }^{1}$ MLCT transitions. The $\lambda_{\max }$ for 
spectra in Figure 3A (extrema denoted by dashed lines) correlate linearly with the Hammett $\operatorname{parameter}^{30}\left(\sigma_{p}\right)$ for each bpy substituent (blue and red curves in Figure 3B; $\Delta v_{\max }=3000 \mathrm{~cm}^{-1}$ ).

Variation in the aryl ligand (rows in Figure 2) also modulates $\lambda_{\max }$ (Figure 3A) $\left(\Delta v_{\max }=1500\right.$ $\mathrm{cm}^{-1}$ ), with increases in electron withdrawing group strength leading to increases in the energy of the ${ }^{1}$ MLCT transitions. While the aryl ligands are all modified at the ortho- position with respect to the $\mathrm{Ni}(\mathrm{II})-\mathrm{C}$ bond, the MLCT $\lambda_{\max }$ correlates with the corresponding meta-Hammett parameter $\left(\sigma_{m}\right)$ (orange line in Figure 3B). This demonstrates a larger contribution of electrostatic and inductive effects over resonance effects upon variation of the aryl substituent relative to bpy. ${ }^{30-36}$ Accordingly, this series (1B-5B) also trends with Taft's field parameter, $\sigma_{F}$ (Figure S7); ${ }^{30}$ for consistency, we use $\sigma_{m}$ in the main text of this manuscript. No linear trend was observed when using Taft's steric $\left(E_{s}\right)$ parameter, ${ }^{30}$ as the aryl ligand and its substituent are rotated orthogonal to the plane of the molecule (Figure S7 and S46). ${ }^{31,36}$
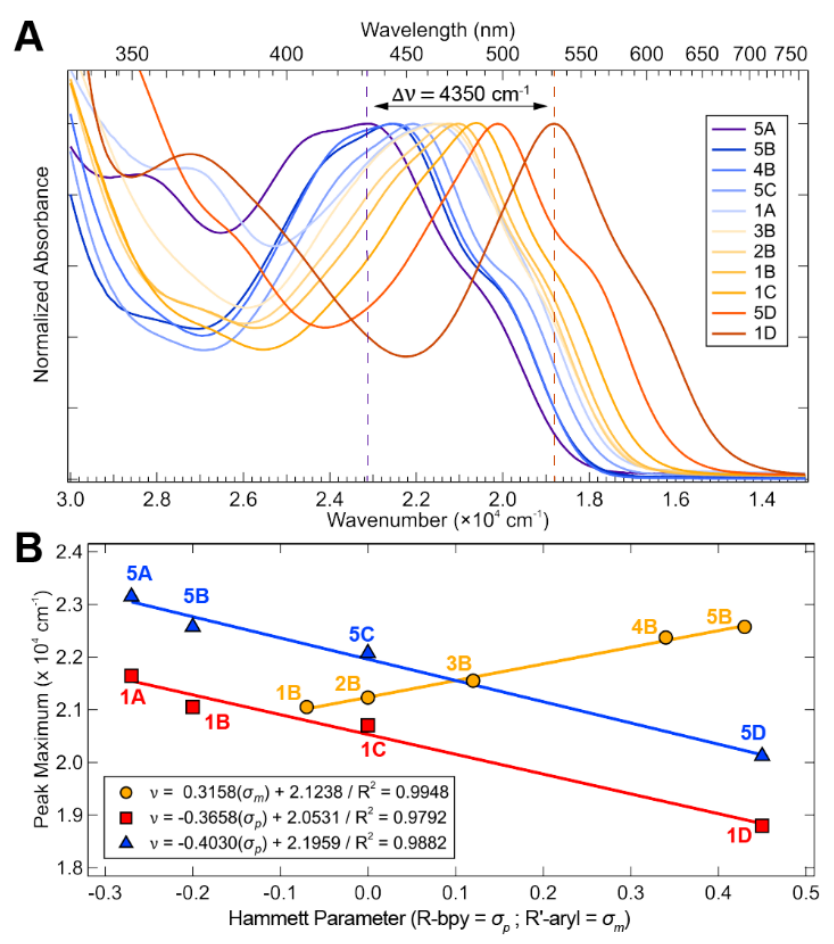
Figure 3. (A) Normalized UV-vis spectra in THF of complexes studied here (overall $\Delta v_{\max }=4350$ $\mathrm{cm}^{-1}$ ). (B) Correlation between $\lambda_{\max }$ (dashed lines in A given for the extrema) in THF and the Hammett parameter $\left(\sigma_{p}\right)$ for each bpy substituent or $\left(\sigma_{m}\right)$ for each aryl substituent. Analogous plots are given in Figure S6 for toluene.

\subsubsection{Photochemical Investigations.}

We first sought to confirm the formation of aryl radicals upon irradiation (see Supporting Information S1.2 for experimental setup). Irradiating well-characterized 1B and analogous 5B at $390 \mathrm{~nm}$ results in distinctive ${ }^{1} \mathrm{H}$ NMR peaks assigned to aryl radical products, 2-(otolyl)tetrahydrofuran, and 2,2'-dimethyl-1,1'-biphenyl (Figure S11-12). ${ }^{21}$ Using ${ }^{19} \mathrm{~F}$ NMR, 5B revealed new peaks associated with the free aryl ligand, concomitant with a loss of aryl peaks in the ${ }^{1} \mathrm{H}$ NMR after $390 \mathrm{~nm}$ irradiation (Figure S14). As demonstrated previously, homolysis does not occur in the absence of light; only minor degradation is observed when the complex is heated to $55^{\circ} \mathrm{C}$ for 60 minutes (Figure S13), but no radical products are observed. ${ }^{21,22} \mathrm{We}$ also noted the formation of radicals upon extended irradiation of the analogous precatalyst complexes, $\mathrm{Ni}(\mathrm{TMEDA})\left({ }^{\prime} \mathrm{Ph}\right) \mathrm{Cl}\left(\mathrm{R}^{\prime}=\mathrm{CH}_{3}, \mathrm{CF}_{3}\right)$, implicating ligand-field excited states as operative for photolysis in the diamine complexes. More detailed discussion regarding this result relative to the photochemistry of Ni(II)-bpy complexes is available in Supporting Information Section S1.6. 

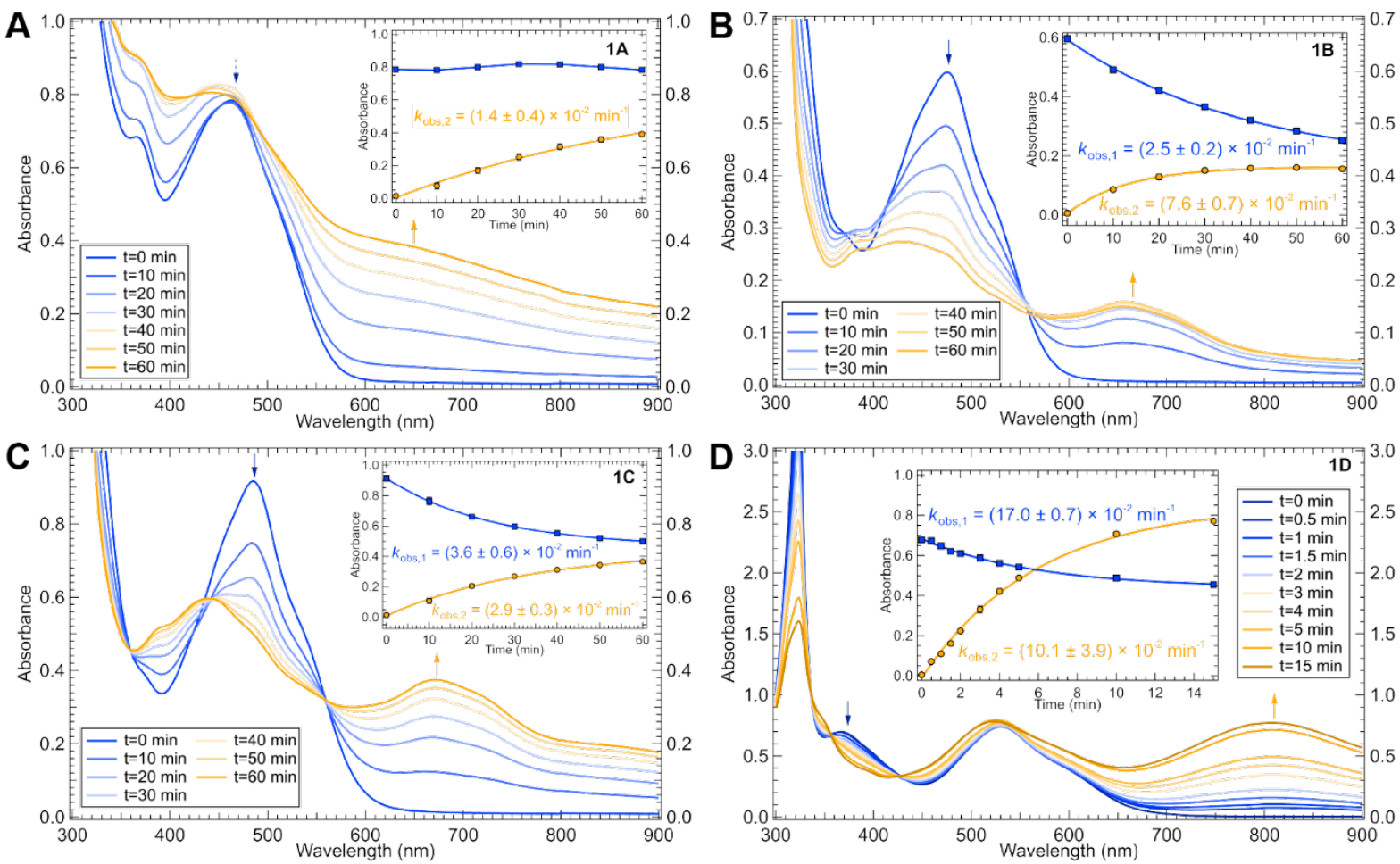

Figure 4. Photolysis profiles of 1A-1D in THF for $390 \mathrm{~nm}$ excitation. Photolysis kinetics were monitored at two wavelengths indicated by the blue and orange arrows in each panel. Insets correspond to the fitted kinetic data (blue curve for the decay of the starting material, orange curve for the formation of the new species). Data were fit using a single exponential; error bars are one standard deviation. For 1A, background scattering from precipitation precluded clear observation of the decay of starting material. This scattering also contributes to the kinetics measured at longer wavelengths for $\mathbf{1 A}$. 

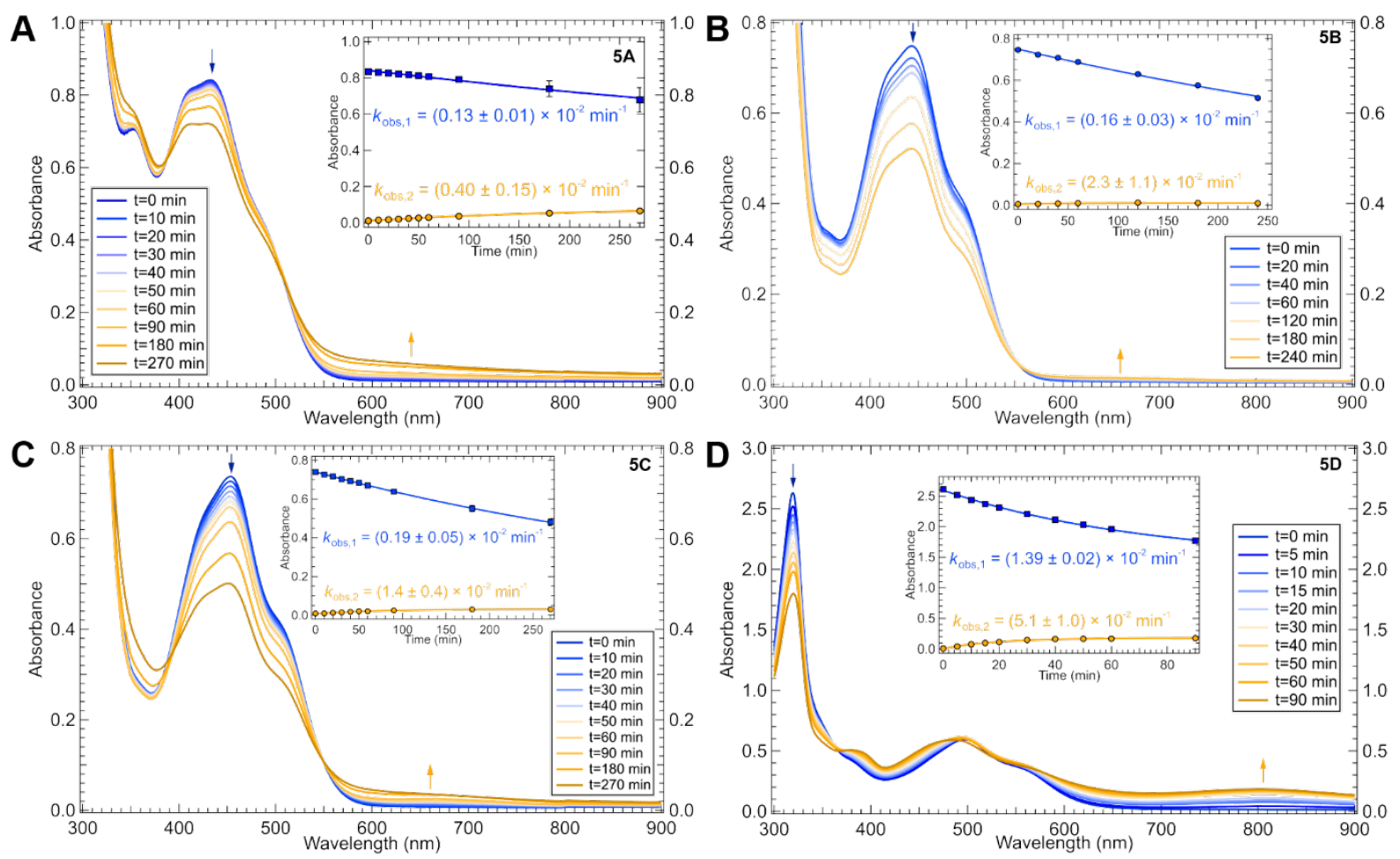

Figure 5. Photolysis profiles of 5A-5D in THF for $390 \mathrm{~nm}$ excitation. Photolysis kinetics were monitored at two wavelengths indicated by the blue and orange arrows in each panel. Insets correspond to the fitted kinetic data (blue curve for the decay of the starting material, orange curve for the formation of the new species). Data were fit using a single exponential; error bars are one standard deviation.

Time-dependent absorption spectra were obtained during photolyses $(390 \mathrm{~nm})$ in THF of all complexes 1A-5D. The data for series 1A-1D, which varies only the bpy substituent, are provided in Figure 4. Photolysis kinetics were monitored at two wavelengths (arrows in Figure 4). From these kinetics, the observed rates $\left(k_{\mathrm{obs}}\right)$ of excited state $\mathrm{Ni}(\mathrm{II})-\mathrm{C}$ bond homolysis can be obtained. Note this series of complexes (1A-1D) has previously been investigated using transient absorption spectroscopy (the only difference being EtOOC versus MeOOC in 1D here). ${ }^{16}$ A clear rate 
dependence is observed upon variation of the bpy ligand (Figure 4 and Table 1). The fastest rate was found in 1D, which underwent photolysis with an observed rate constant of $k_{\mathrm{obs}, 1}=(17.0 \pm$ 0.7) $\times 10^{-2} \mathrm{~min}^{-1}$. Compounds $\mathbf{1 A}-\mathbf{1 C}$ presented smaller, but noticeable, differences in their decay rates (Table 1). For $\mathbf{1 A}$, background scattering from precipitation precluded clear observation of the decay of starting material.

Excited state homolysis of the $\mathrm{Ni}(\mathrm{II})-\mathrm{C}$ bond yielded a new product with absorbance in the visible region for each compound. Isosbestic points are observed in the photolysis data for all compounds studied here except $\mathbf{1 A}$, where light scattering contributes to the time-dependent spectra. While the general absorption profiles of these new species are similar, the primary low energy features shift from $\sim 650 \mathrm{~nm}$ in $\mathbf{1 A}$ to $805 \mathrm{~nm}$ for 1D (Figure 4). The spectral shift over this series suggests the bpy ligand is present in the new species.

The analogous time-dependent UV-vis spectra for compounds 5A-5D are given in Figure 5. Again using $390 \mathrm{~nm}$ excitation, there are significant changes in the rate of excited state $\mathrm{Ni}(\mathrm{II})-\mathrm{C}$ bond homolysis across these compounds, with $k_{\mathrm{obs}, 1}$ varying over an order of magnitude (Figure 5, Table 1). However, these compounds generally exhibit much slower rates than the complementary 1A-1D series. Thus, the electron withdrawing effect of the aryl ligand also impacts the rate. The growth of a new species was also observed for these complexes $(\sim 650 \mathrm{~nm}$ in $\mathbf{5 A}$ to $805 \mathrm{~nm}$ in $\mathbf{5 D}$ (Figure 5)), albeit at significantly lower quantities.

To further investigate the dependence of $k_{\mathrm{obs}, 1}$ on variation of the aryl ligand, analogous timedependent UV-vis data were obtained for complexes 2B-4B (Figure 6). From these data, the full trend is revealed: increasing the electron withdrawing nature of the aryl ligand (left to right in the row of Figure 2) again resulted in slower rates across the series. This behavior is opposite to that observed for variations in the electron withdrawing effect of the bpy ligand, hence the opposite 
slopes in Figure 3B. Note also the primary low energy absorption feature of the new species is not dependent on the aryl ligand $(\lambda=660 \mathrm{~nm}$ for 1B-5B, Figures S37-39).
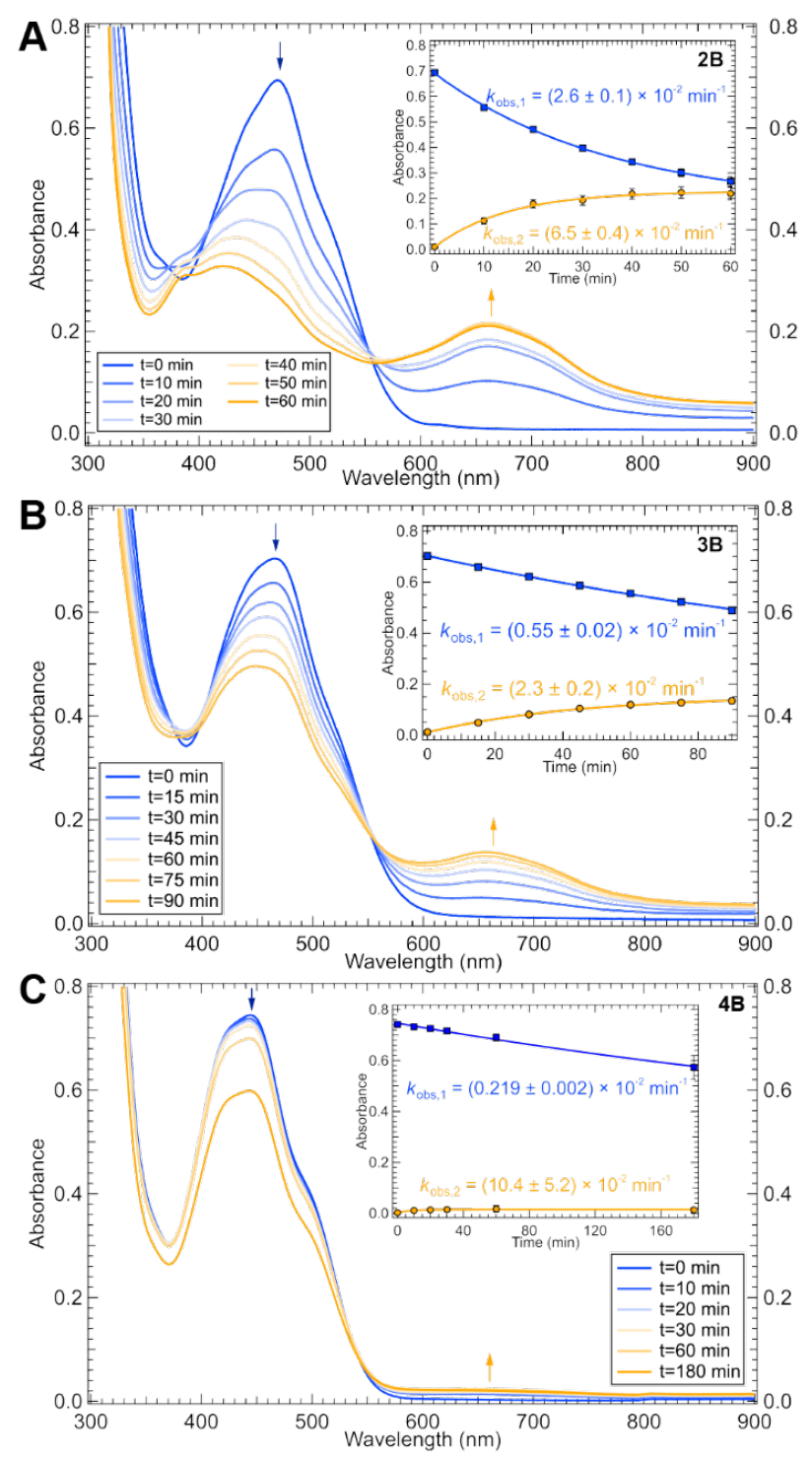

Figure 6. Photolysis profiles of 2B-4B in THF using $390 \mathrm{~nm}$ excitation. Photolysis kinetics were monitored at two wavelengths indicated by the blue and orange arrows in each panel. Insets correspond to the fitted kinetic data (blue curve for the decay of the starting material, orange curve for the formation of the new species). Data were fit using a single exponential; error bars are one standard deviation. 
We note that in certain regions, the absorption spectrum of the photolysis product overlaps with that of the starting material, including where decay kinetics are measured (blue arrows in Figures 4-6). To deconvolute the spectral overlap, global kinetics modeling was carried out (full discussion and details of the kinetic modeling are available in Supporting Information Section S1.9). Good agreement is seen between the observed rate constants and those obtained from the global fits, and the kinetic trends across the matrix of compounds are preserved (Figure S36). Comparison between $k_{\mathrm{obs}, 1}$ and rates from global fitting $\left(k_{\mathrm{p}}\right)$ are also given in Table 1.

In summary, electronically stabilizing the $\mathrm{Ni}(\mathrm{II})$-to-bpy MLCT transition energies by increasing the bpy-based electron withdrawing effect accelerated the rate of photolysis. Also, increasing the aryl-based electron withdrawing effect conversely resulted in increased MLCT transition energies and slower rates of photolysis (see the oppositely signed slopes in Figure 3B). These data reflect competing effects on the excited state PESs involved in homolysis and are further described in the computational sections below. Furthermore, the rate of excited state Ni(II)C bond homolysis correlates linearly with specific Hammett parameters of the bpy and aryl ligands. As shown in Figure 7, linear relationships are observed upon plotting $\log \left(k_{\mathrm{obs}, 1} / k_{\mathrm{obs}, 1}(\mathrm{H})\right)$ versus $\sigma_{p}$ or $\sigma_{m}$ (for ${ }^{\mathrm{R}}$ bpy or ${ }^{\mathrm{R}} \mathrm{Ph}$, respectively) $\left(\mathrm{R}^{2} \geq 0.95\right)\left(\rho=\sim 1.4\right.$ for ${ }^{\mathrm{R}}$ bpy and $\rho=\sim-2.6$ for $\left.{ }^{\mathrm{R}} \mathrm{Ph}\right)$. Thus, the rate of excited state $\mathrm{Ni}(\mathrm{II})-\mathrm{C}$ homolysis is sensitive to electronic structure perturbations from both the bpy and aryl ligands. 


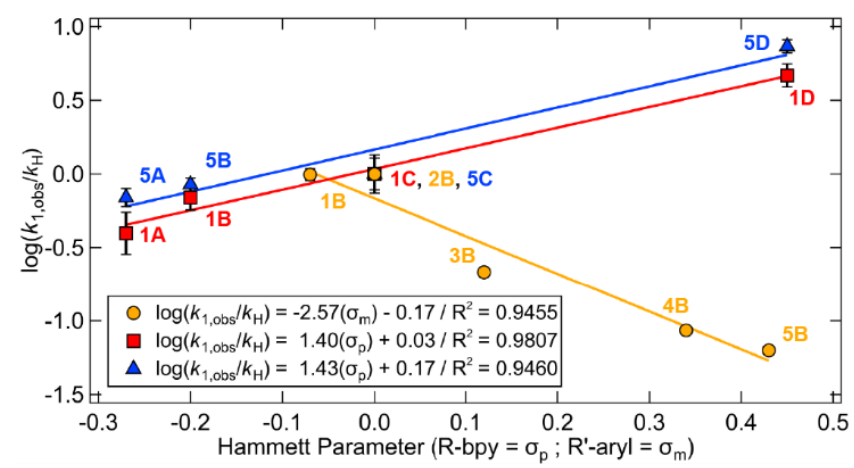

Figure 7. Correlation between normalized rates of excited state bond homolysis and specific Hammett $\sigma$ parameters of the bpy and aryl ligands. Note that in $\mathbf{1 A}$, the rate is approximated by $k_{2, \text { obs. }}$

Table 1. Summary of UV-vis $\lambda_{\max }$ and first-order rate constants. Solvent $=$ THF. Errors are listed as one standard deviation over three trials.

\begin{tabular}{|c|c|c|c|c|c|}
\hline Compound & $\begin{array}{c}\lambda_{\text {MLCT }} \\
(\mathbf{n m})\end{array}$ & $\begin{array}{l}\mathbf{v}_{\mathrm{MLCT}} \\
\left(\mathbf{c m}^{-1}\right)\end{array}$ & $\begin{array}{c}k_{\text {obs, } 1} \\
\left(\times 10^{-2} \text { min }^{-1}\right)\end{array}$ & $\begin{array}{c}k_{\mathrm{p}} \\
\left(\mathrm{x} 10^{-2} \min ^{-1}\right)\end{array}$ & $\begin{array}{c}k_{\text {obs, }, 2} \\
\left(\times 1^{-2} \min ^{-1}\right)\end{array}$ \\
\hline $\mathbf{1 A}$ & 462 & 21645 & n.d..$^{\mathrm{a}}$ & $0.9 \pm 0.1$ & $1.4 \pm 0.4$ \\
\hline 1B & 475 & 21053 & $2.5 \pm 0.2$ & $4.1 \pm 0.4$ & $7.6 \pm 0.7$ \\
\hline $1 \mathrm{C}$ & 483 & 20704 & $3.6 \pm 0.6$ & $3.3 \pm 0.5$ & $2.9 \pm 0.3$ \\
\hline 1D & 532 & 18797 & $17.0 \pm 0.7$ & $15.0 \pm 0.8$ & $10.1 \pm 3.9$ \\
\hline 2B & 471 & 21231 & $2.6 \pm 0.1$ & $4.4 \pm 0.1$ & $6.5 \pm 0.4$ \\
\hline 3B & 464 & 21552 & $0.55 \pm 0.02$ & $1.6 \pm 0.1$ & $2.3 \pm 0.2$ \\
\hline 4B & 447 & 22371 & $0.219 \pm 0.002$ & $0.14 \pm 0.18$ & $10.4 \pm 5.2$ \\
\hline $5 \mathrm{~A}$ & 432 & 23148 & $0.13 \pm 0.01$ & $0.08 \pm 0.03$ & $0.40 \pm 0.15$ \\
\hline 5B & 443 & 22573 & $0.16 \pm 0.03$ & n.d. ${ }^{b}$ & $2.3 \pm 1.1$ \\
\hline $5 \mathrm{C}$ & 453 & 22075 & $0.19 \pm 0.05$ & $0.16 \pm 0.01$ & $1.4 \pm 0.4$ \\
\hline 5D & 497 & 20121 & $1.39 \pm 0.02$ & $3.0 \pm 0.5$ & $5.1 \pm 1.0$ \\
\hline 1B-Br & 479 & 20877 & $6.9 \pm 0.4$ & $8.1 \pm 0.8$ & $9.2 \pm 0.7$ \\
\hline
\end{tabular}

${ }^{\text {a Because the new species formed upon } \mathrm{Ni}(\mathrm{II})-\mathrm{C} \text { bond homolysis has absorption underneath that }}$ of the starting material, we were unable to obtain $k_{1, \text { obs }}$ for this compound. The rate is approximated by $k_{2, \text { obs. }}{ }^{\mathrm{b}}$ Complex $\mathbf{5 B}$ was omitted owing to poor convergence of the global kinetics model. 


\subsubsection{Preliminary Investigations of the Photochemically Generated Species.}

The immediate product of $\mathrm{Ni}(\mathrm{II})-\mathrm{C}$ bond homolysis has been proposed to be a three-coordinate $\mathrm{Ni}(\mathrm{I})^{\mathrm{R}}$ bpy $(\mathrm{Cl})$ complex. A recent study by Bird et al. on the related $\left.\mathrm{Ni}(\mathrm{I}){ }^{(-\mathrm{Bu}} \mathrm{bpy}\right) \mathrm{Br}$ reported its UV-vis spectrum as generated by pulse radiolysis or electrolysis. ${ }^{37}$ For direct comparison, we synthesized $\mathrm{Ni}\left({ }^{-\mathrm{Bu}}\right.$ bpy $)\left(\mathrm{CH}_{3} \mathrm{Ph}\right) \mathrm{Br}, \mathbf{1 B}-\mathbf{B r}$, and subjected it to the same photolysis conditions as above. We found a roughly three-fold enhancement in the rate of photolysis for $\mathbf{1 B}-\mathbf{B r}\left(k_{\mathrm{obs}, 1}=\right.$ $\left.(6.9 \pm 0.4) \times 10^{-2} \mathrm{~min}^{-1}\right)$ relative to $\mathbf{1 B}\left(k_{\mathrm{obs}, 1}=(2.5 \pm 0.2) \times 10^{-2} \mathrm{~min}^{-1}\right)$ and a change in the absorption spectrum of the product species (Figure 8A). The primary low energy absorption feature of the product appears at higher energy when produced from the bromo-complex $(653 \mathrm{~nm})$ versus the chloro-complex $(660 \mathrm{~nm})$. Thus, there is a halide-dependence on the absorption spectrum of the product compound. A comparison between the long-time spectra of the photoproducts from compounds $\mathbf{1 B}-\mathbf{B r}, \mathbf{1 B}, \mathbf{3 B}, \mathbf{1 C}$, and $\mathbf{1 D}$ is given in Figure 8B, illustrating a change in peak maxima when changing the bpy or halide ligands, but not the aryl ligand.

We also followed the photolysis of $\mathbf{1 B}-\mathbf{B r}$ in dimethylformamide (DMF), the same solvent used by Bird et al. (Figure S42). ${ }^{37} \mathrm{We}$ first note the steady state UV-vis data are solvatochromic, with the main MLCT bands being lower in energy in THF relative to DMF (Figure 8C, blue versus purple lines, respectively). The homolysis product UV-vis spectra are also solvatochromic. In particular, DMF solutions exhibit the same characteristic UV-vis features for the three-coordinate monomeric species $(430,620$, and $860 \mathrm{~nm})$ as observed by Bird et al. (Figure $8 \mathrm{C}$, green line). We further note that the rate of excited state $\mathrm{Ni}(\mathrm{II})-\mathrm{C}$ bond homolysis is slower in $\mathrm{DMF}$ relative to THF. We tentatively ascribe these differences in rates to changes in the MLCT energies and overall excited state PESs (vide infra). These interesting solvent effects on the excited state PESs and, thus, rates of homolysis are currently under more detailed investigation. 
Therefore, we postulate that the new species formed here upon excited state $\mathrm{Ni}(\mathrm{II})-\mathrm{C}$ homolysis are three-coordinate $\mathrm{Ni}(\mathrm{I})\left({ }^{\mathrm{R}}\right.$ bpy $) \mathrm{X}$ complexes $(\mathrm{R}=\mathrm{MeO}, \mathrm{t}-\mathrm{Bu}, \mathrm{H}$, and $\mathrm{MeOOC}, \mathrm{X}=\mathrm{Cl}$ or $\mathrm{Br}$ ), as it has been shown by steady-state UV-vis spectroscopy to 1) contain the bpy ligand, 2) not contain the aryl ligand, 3) contain the halide, and 4) exhibit the same absorption profile as $\mathrm{Ni}(\mathrm{I})\left({ }^{(-B u}\right.$ bpy $) \mathrm{Br}$ in the case of $\mathbf{1 B}-\mathbf{B r}$. A detailed comparative study of the reactivities and further spectroscopic characterizations of these species is currently underway.
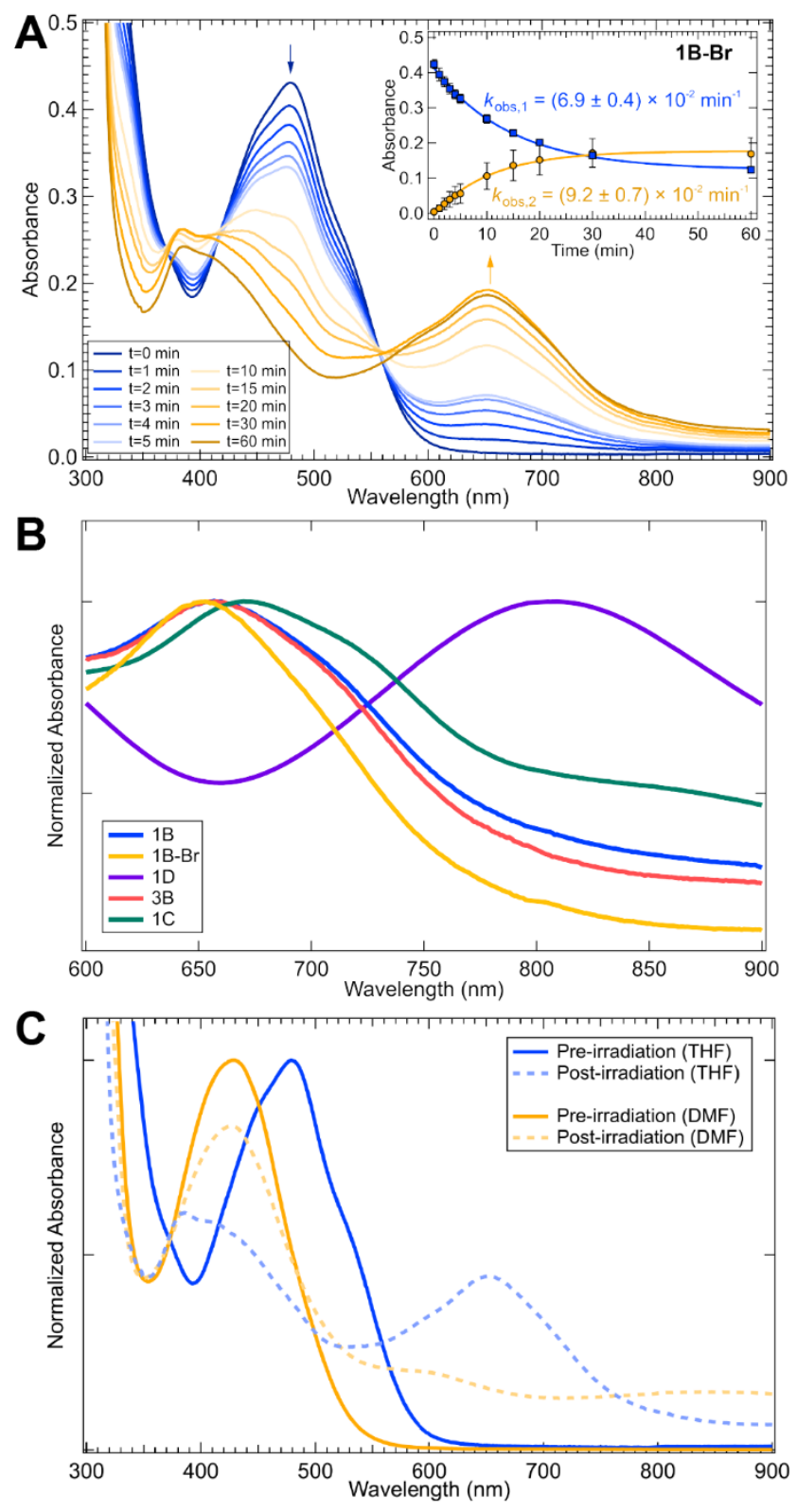
Figure 8. (A) Photolysis profile of 1B-Br in THF (390 nm excitation) monitored at two wavelengths indicated by the blue and orange arrows in each panel. Inset corresponds to the firstorder kinetics data (blue curve for the decay of the starting material, orange curve for the formation of the new species). Error bars are one standard deviation. (B) Comparison between long-time UVvis spectra for 1B-Br $\left(\lambda_{\max }=653 \mathrm{~nm}\right), \mathbf{1 B}\left(\lambda_{\max }=660 \mathrm{~nm}\right), \mathbf{3 B}\left(\lambda_{\max }=660 \mathrm{~nm}\right), \mathbf{1 C}\left(\lambda_{\max }=673\right.$ $\mathrm{nm})$, and 1D $\left(\lambda_{\max }=805 \mathrm{~nm}\right)(\mathrm{C})$ Comparison between UV-vis spectra for 1B-Br in THF and DMF, before and after irradiation with $390 \mathrm{~nm}$ light.

\subsubsection{Further Examination of the Mechanism of Excited State Bond Homolysis.}

To further investigate the mechanism of excited state $\mathrm{Ni}(\mathrm{II})-\mathrm{C}$ bond homolysis, we carried out temperature-dependent photolyses of $\mathbf{1 B}$ and $\mathbf{1 B}-\mathbf{B r}$. Among the matrix of complexes studied here, these two are most often utilized for synthetic applications, giving their analyses direct implications for photoredox catalysis. ${ }^{22}$ Eyring plots of temperature dependent rates for these complexes are given in Figure 9. From these data, the enthalpy and entropy of activation for the excited state $\mathrm{Ni}(\mathrm{II})-\mathrm{C}$ bond homolysis in $\mathbf{1 B}$ are $\Delta \mathrm{H}^{\ddagger}=4.4 \pm 0.6 \mathrm{kcal} \mathrm{mol}^{-1}$ and $\Delta \mathrm{S} \ddagger(298 \mathrm{~K})=-45.3$ $\pm 1.8 \mathrm{cal} \mathrm{mol}^{-1}$, with $\Delta \mathrm{G}^{\dagger}=17.9 \pm 0.8 \mathrm{kcal} \mathrm{mol}^{-1}$. Eyring analysis of $\mathbf{1 B}-\mathbf{B r}$ gives $\Delta \mathrm{H}^{\ddagger}=2.1 \pm 0.1$ kcal $\mathrm{mol}^{-1}$ and $\Delta \mathrm{S}^{\ddagger}(298 \mathrm{~K})=-49.3 \pm 0.4 \mathrm{cal} \mathrm{mol}^{-1}$, with $\Delta \mathrm{G}^{*}=16.8 \pm 0.2 \mathrm{kcal} \mathrm{mol}^{-1}$. At high temperatures $(328 \mathrm{~K})$, thermal decay of the starting material occurs for $\mathbf{1 B}-\mathbf{B r}$, resulting in a downturn in the temperature-dependent rates (dashed yellow line, Figure 9). Because of this, the linear fit utilized a room temperature point. As expected, the barrier for excited state $\mathrm{Ni}(\mathrm{II})-\mathrm{C}$ bond homolysis is lower in $\mathbf{1 B}-\mathbf{B r}$ than $\mathbf{1 B}$, consistent with its faster rate. Note these data represent the first experimental measurements of the thermodynamic parameters associated with excited state $\mathrm{Ni}(\mathrm{II})-\mathrm{C}$ bond homolysis in Ni-based photoredox catalysts. 


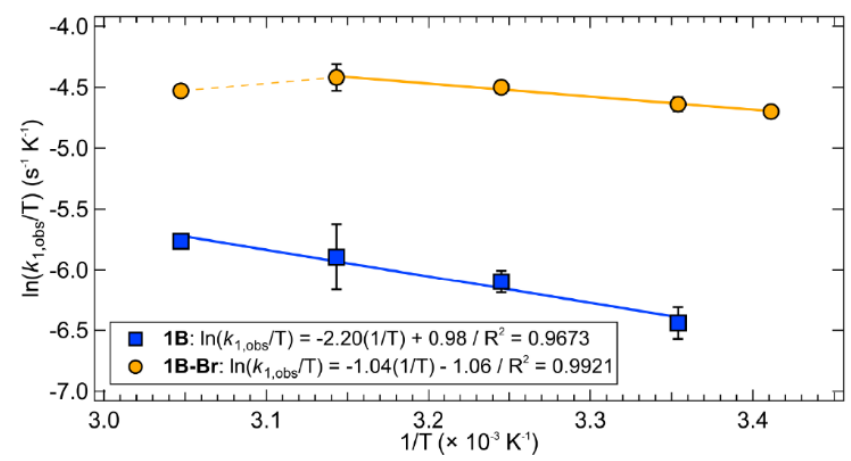

Figure 9. Eyring analysis of the temperature dependent photolysis rates of $\mathbf{1 B}$ (blue, squares) and 1B-Br (orange, circles); error bars are one standard deviation over three trials.

In addition to being dependent on temperature, the rate of excited state bond homolysis in $\mathbf{1 B}$ is also highly dependent on the excitation wavelength (Table 2, Figure 10A). Varying incident wavelengths (390, 427, 456, and $525 \mathrm{~nm}$, Figure S19) revealed a minimum energy threshold for excited state $\mathrm{Ni}(\mathrm{II})-\mathrm{C}$ bond homolysis of $\sim 55 \mathrm{kcal} \mathrm{mol}^{-1}\left(525 \mathrm{~nm}, 19050 \mathrm{~cm}^{-1}\right)$ in 1B; below this incident energy, no homolysis is observed (Figure S20). Previous optical transient absorption measurements on 1B were carried out using $\lambda_{\text {pump }}=530 \mathrm{~nm} \cdot{ }^{16}$ Laser excitation at this wavelength results in the formation of a $\mathrm{Ni}(\mathrm{II})$-based triplet ligand field excited state, from which homolysis was proposed on the basis of DFT calculations. Notably, however, very limited photolysis occurs here using a $525 \mathrm{~nm}$ excitation light source. These results demonstrate that the lower-energy ligand field state is not responsible for excited state $\mathrm{Ni}(\mathrm{II})-\mathrm{C}$ bond homolysis, but rather indicate the involvement of higher-energy excited states.

To search for general trends across compounds considered here, we also conducted wavelength dependent studies on 1D and 5D (Figure 10B-C). Together, these complexes span a wide range of photolysis rates, have varying MLCT transition energies, and feature electronic structure differences provided by the bpy and aryl ligands. In each case, a clear wavelength dependence was 
observed, and high energy incident light was required for homolysis. No appreciable decay was observed using low energy light (Figures S20-22), again implicating high energy excited states in the mechanism of light-induced homolysis.
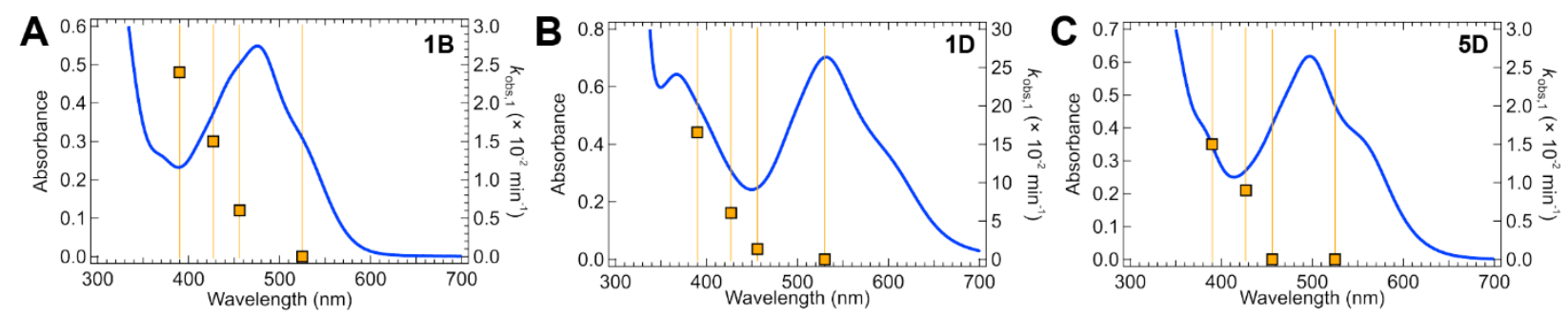

Figure 10. Wavelength-dependent photolysis for 1B, 1D, and 5D. The absorption spectra are shown in blue; the observed photolysis rates (squares) and incident wavelengths are given in orange.

In summary, through experimental analyses of a matrix of $\mathrm{Ni}(\mathrm{II})$-bpy aryl halide complexes, we have demonstrated the following: 1) a linear dependence between $\lambda_{\max }$ in the visible region and the Hammett parameters of the bpy and aryl substituents over the 1A-5D series (Figure 3B), 2) a linear correlation between the Hammett parameters of the bpy and aryl substituents and the rate of excited state $\mathrm{Ni}(\mathrm{II})-\mathrm{C}$ bond homolysis over the 1A-5D series (Figure 7), interestingly with oppositely signed slopes, 3 ) the barrier for excited state bond homolysis is moderate (e.g., $\Delta \mathrm{H}^{*}=$ $4.4 \pm 0.6 \mathrm{kcal} \mathrm{mol}^{-1}$ in $\mathbf{1 B}$ using $390 \mathrm{~nm}$ excitation; Figure 9), and 4) the excited state bond homolysis is distinctly wavelength dependent (Figure 10), requiring a minimum of $\sim 55 \mathrm{kcal} \mathrm{mol}^{-}$ ${ }^{1}\left(525 \mathrm{~nm}, 19050 \mathrm{~cm}^{-1}\right)$ in 1B. These experimental observations are discussed below in the context of computational studies, which further aid in the elucidation of the mechanism of excited state $\mathrm{Ni}(\mathrm{II})-\mathrm{C}$ bond homolysis. 


\subsection{Computational Studies.}

In the following computational Sections 2.2.1-2.2.3, we first compare the ground and excited state properties of $\mathbf{1 A}-\mathbf{5 D}$ computed at different levels of theory. We discuss the possible photoactivation pathways that are accessible in the energy range of the external light sources used in the photolysis experiments, as well as those pathways that are consistent with the experimental barrier. Notably, the incident light energy required for photolysis (as determined from wavelength dependent kinetic experiments) is substantially greater than the energy of the ${ }^{3}(\mathrm{~d}-\mathrm{d})$ bands in $\mathbf{1 A}-$ 5D, and the calculated barriers for homolysis from these states are significantly larger than experiment. These points indicate thermally-driven excited state $\mathrm{Ni}(\mathrm{II})-\mathrm{C}$ bond homolysis from a spin-forbidden ligand field state is not the operative mechanism. Instead, we focus on the possible photolysis pathways that exploit triplet excited state LMCT-based repulsive PESs. We propose a working mechanism that can ultimately be described as ${ }^{1} \mathrm{MLCT}\left[\mathrm{Ni} \mathrm{d} \rightarrow\right.$ bpy $\left.\pi^{*}(2)\right]$ excitation followed by surface hopping to a repulsive ${ }^{3}$ LMCT (aryl-to-Ni) PES ( ${ }^{3}$ MLCT+LMCT). This mechanism is in agreement with the experimentally derived reaction rates and thermodynamic barriers determined herein.

\subsubsection{DFT versus CASSCF/QD-NEVPT2 Ground and Excited States.}

To evaluate the geometric and electronic structures of $\mathbf{1 A}-\mathbf{5 D}$, we compared their ground and excited state properties calculated with either DFT/TD-DFT or ab initio complete active space self-consistent field theory with the quasidegenerate $N$-electron valence state perturbation theory correction (CASSCF/QD-NEVPT2) ${ }^{38-41}$; full computational details are available in Supporting Information Section S2.1. 
With DFT (B3LYP) ${ }^{42-44}$, all Ni(II) complexes are correctly predicted to have low-spin, singlet $(\mathrm{S}=0)$ ground states with square-planar geometries (note the $\mathrm{x}$-axis is directed along the $\mathrm{Ni}$-halide bond and the $\mathrm{y}$-axis is along the $\mathrm{Ni}$-aryl bond). The fully optimized triplet $(\mathrm{S}=1)$ ligand field excited states are in all cases $\sim 10 \mathrm{kcal} \mathrm{mol}^{-1}$ higher in energy with pseudo-tetrahedral geometries. The electronic configuration of the ground state is $[\mathrm{d}(\mathrm{xy})]^{2}[\mathrm{~d}(\mathrm{yz})]^{2}[\mathrm{~d}(\mathrm{xz})]^{2}\left[\mathrm{~d}\left(\mathrm{z}^{2}\right)\right]^{2}$, with three unoccupied bpy-based $\pi^{*}$ orbitals and a highly covalent antibonding $\left[\mathrm{d}\left(\mathrm{x}^{2}-\mathrm{y}^{2}\right) / \mathrm{C}\left(\mathrm{sp}^{2}\right)^{*}\right]^{0}$ orbital (see Figure S50 for an example molecular orbital diagram for 1D). The orbital energies are modulated by the bpy substituents; increasing the electron withdrawing effect of the bpy ligand (columns in Figure 2) decreases the energies of the bpy $\pi^{*}$ orbitals, reducing the $\mathrm{Ni}(\mathrm{II})$-to-bpy MLCT energy (Figure S51), consistent with the red-shifted experimental $\lambda_{\max }$ features in Figure 3 across both the 1A-5A and 1D-5D series. On the other hand, the HOMO and the bpy $\pi^{*}$ orbital energies remain essentially unchanged when modulating the aryl substituent (rows in Figure 2), contrasting with the blue shift in Figure 3. The correct behavior can be recovered at the TD-DFT level, which accounts for orbital mixing in the excited states (Figure S53). Interestingly, the changes in orbital energies are not translated into changes in the covalencies of the ground states, which remain $\sim 51-54 \% \mathrm{Ni}$ d and $\sim 11-13 \%$ bpy character for 1A-5D (Table S7).

The calculated TD-DFT absorption spectra agree well with the experimental UV-vis data (see overlaid spectra in Figure S53) and also demonstrate a similar linear relationship with the substituent-specific Hammett $\sigma$ parameters (Figure 11, top). The broad feature at longer wavelengths $(\sim 400-600 \mathrm{~nm})$ encompasses all the 'low-energy' ${ }^{1}$ MLCT transitions [Ni d $\rightarrow$ bpy $\left.\pi^{*}(1)\right]$, with [d(yz) $\rightarrow$ bpy $\left.\pi^{*}(1)\right]$ having the highest calculated oscillator strength. The shoulder at $\sim 350-370 \mathrm{~nm}$ apparent in most of the experimental UV-vis spectra of 1A-5D can be similarly assigned to a $\left[\mathrm{d}(\mathrm{yz}) \rightarrow\right.$ bpy $\left.\pi^{*}(2)\right]$ transition; other 'high-energy' ${ }^{1} \mathrm{MLCT}$ 
[Ni d $\rightarrow$ bpy $\left.\pi^{*}(2)\right]$ transitions are predicted to fall in the $\sim 300-450 \mathrm{~nm}$ range. The ${ }^{1}(\mathrm{~d}-\mathrm{d})$ transitions are calculated to be comparable in energy to the 'low-energy' ${ }^{1}$ MLCT bands ( $\sim 400$ $500 \mathrm{~nm}$ ) and are not visible in the experimental UV-vis spectra of $\mathbf{1 A - 5 D}$. This assignment is also consistent with the energy of the observable ${ }^{1}(\mathrm{~d}-\mathrm{d})$ band $\left[\mathrm{d}(\mathrm{yz}) \rightarrow \mathrm{d}\left(\mathrm{x}^{2}-\mathrm{y}^{2}\right) / \mathrm{C}\left(\mathrm{sp}^{2}\right)^{*}\right]$ in the $\mathrm{Ni}(\mathrm{II})(\mathrm{TMEDA})\left(\mathrm{CH}_{3} \mathrm{Ph}\right) \mathrm{Cl}$ complex that is detected in the visible range at $\sim 470 \mathrm{~nm}$ (calculated at $533 \mathrm{~nm}$ ); the less intense bands observed near $\sim 635 \mathrm{~nm}$ can be assigned to the spin-forbidden triplet transitions. For example, the $\left[\mathrm{d}(\mathrm{xy}) \rightarrow \mathrm{d}\left(\mathrm{x}^{2}-\mathrm{y}^{2}\right) / \mathrm{C}\left(\mathrm{sp}^{2}\right)^{*}\right]$ triplet transition is calculated at $642 \mathrm{~nm}$. Others, including $\left[\mathrm{d}(\mathrm{xz}) \rightarrow \mathrm{d}\left(\mathrm{x}^{2}-\mathrm{y}^{2}\right) / \mathrm{C}\left(\mathrm{sp}^{2}\right)^{*}\right]$ and $\left[\mathrm{d}(\mathrm{yz}) \rightarrow \mathrm{d}\left(\mathrm{x}^{2}-\mathrm{y}^{2}\right) / \mathrm{C}\left(\mathrm{sp}^{2}\right)^{*}\right]$, are calculated at $847 \mathrm{~nm}$ and $945 \mathrm{~nm}$, respectively. All relevant TD-DFT electronic transition energies are given in Table S8.

Therefore, the light sources exhibiting most appreciable excited state $\mathrm{Ni}(\mathrm{II})-\mathrm{C}$ bond homolysis (390 and $427 \mathrm{~nm}$ ) in 1A-5D favor initial excitation into high-energy ${ }^{1}$ MLCT bands, [Ni d $\rightarrow$ bpy $\pi^{*}(2)$ ], while longer wavelength light sources from the wavelength dependence study in Figure 10 (456 and $525 \mathrm{~nm}$ ) are in the range of the low-energy ${ }^{1}$ MLCT bands, [Ni d $\rightarrow$ bpy $\left.\pi^{*}(1)\right]$. Therefore, the minimum energy threshold of $\sim 525 \mathrm{~nm}$, below which no photolysis is observed, is not consistent with the previous DFT-based assignment of bond rupture from a low-lying triplet ligand field state (Figure 1B, left). ${ }^{16}$ 

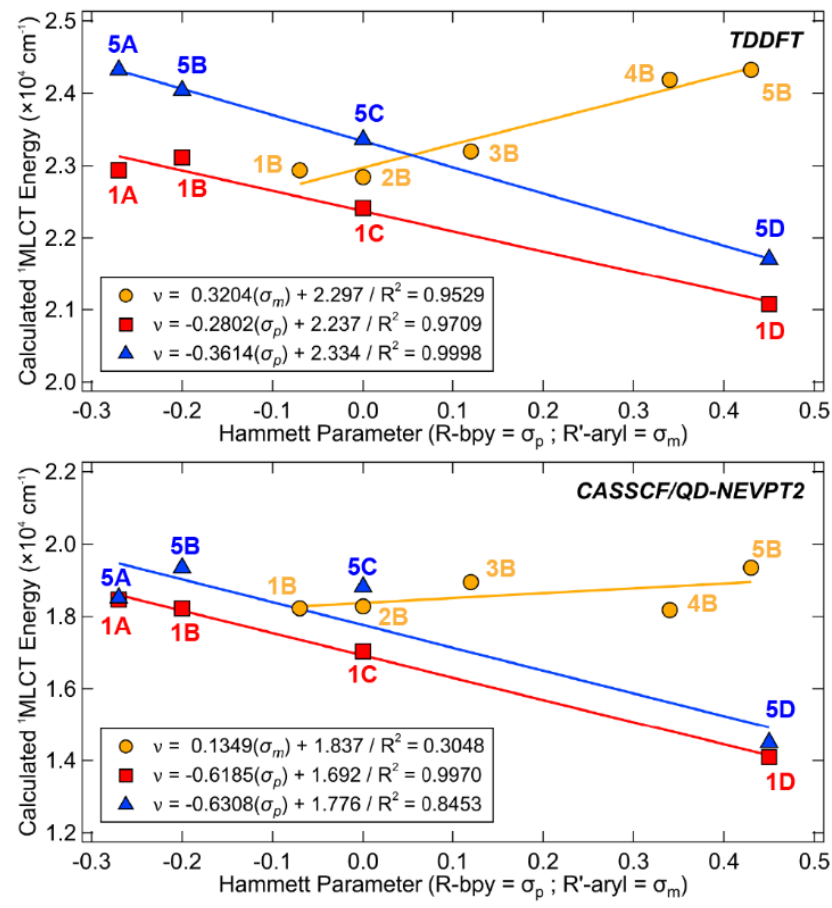

Figure 11. Correlation between the calculated ${ }^{1} \operatorname{MLCT}\left[\mathrm{d}(\mathrm{yz}) \rightarrow \pi^{*}(1)\right]$ transition energies (CPCM solvation model, THF) and the specific Hammett $\sigma$ parameters using both TD-DFT (top) and CASSCF/QD-NEVPT2 (bottom) methods.

Multiconfigurational/multireference CASSCF/QD-NEVPT2 calculations were conducted using the DFT-optimized singlet geometries. State-averaged CASSCF calculations (15 singlets, 25 triplets) were performed with an active space of 10 electrons in 9 orbitals $(10 \mathrm{e}, 9 \mathrm{o}): \mathrm{d}(\mathrm{yz}), \mathrm{d}\left(\mathrm{z}^{2}\right)$, $\mathrm{d}(\mathrm{xy}), \mathrm{d}(\mathrm{xz})$, a pair of bonding and antibonding $\mathrm{Ni} \mathrm{d}\left(\mathrm{x}^{2}-\mathrm{y}^{2}\right) /$ aryl $\mathrm{C}\left(\mathrm{sp}^{2}\right)$ orbitals, and three bpy $\pi^{*}$ orbitals (Figure S47). The method and active space follow our previous study on $\mathbf{1 B} .{ }^{27}$ For $\mathbf{1 A}-$ 5D, the ground state wave functions exhibit substantial multiconfigurational character. While the configuration interaction (CI) vectors (Figure S48, Table S7) are primarily comprised of the closed-shell singlet (CSS) configuration (i.e., the configuration also acquired with DFT), both the MLCT and LMCT configurations contribute significantly to the character of the ground state wave 
function (CSS $\sim 60 \%$, sum of all MLCTs $\sim 15-25 \%$ with primary representation of $\left[\mathrm{d}(\mathrm{yz}) \rightarrow \pi^{*}(1)\right]$ and $\left[\mathrm{d}(\mathrm{xz}) \rightarrow \pi^{*}(1)\right]$ configurations, and LMCT $\left[\mathrm{d}\left(\mathrm{x}^{2}-\mathrm{y}^{2}\right) / \mathrm{C}\left(\mathrm{sp}^{2}\right) \rightarrow \mathrm{d}\left(\mathrm{x}^{2}-\mathrm{y}^{2}\right) / \mathrm{C}\left(\mathrm{sp}^{2}\right)^{*}\right]$ of $\left.\sim 13 \%\right)$.

The calculated CASSCF/QD-NEVPT2 absorption spectra generally agree fairly well with the observed bands in the experimental UV-vis data (Figure S54, tabulated in Table S9). However, the $\lambda_{\max }$ are notably red-shifted $\left(\sim 5000 \mathrm{~cm}^{-1}\right)$ as compared with TD-DFT (Figure S51 and Table S8). The composition of the ground state CI vector, particularly the total ${ }^{1}$ MLCT contribution, also closely correlates with the transition energy in the calculated UV-vis spectra. As the ${ }^{1}$ MLCT $\left[\mathrm{Nid}(\mathrm{xz}) \rightarrow\right.$ bpy $\left.\pi^{*}(1)\right]$ weight increases, the calculated energy of $\lambda_{\max }$ in the absorption spectrum decreases (Figure S56). The multiconfigurational/multireference calculations also demonstrate a similar linear relationship with the substituent-specific Hammett $\sigma$ parameters (Figure 11, bottom).

\subsubsection{Investigating the Mechanism of Excited State Ni(II)-C Bond Homolysis.}

DFT relaxed PES scans along the $\mathrm{Ni}(\mathrm{II})-\mathrm{C}$ bond coordinates of $\mathbf{1 A}-\mathbf{5 D}$ revealed a singlet/triplet degenerate homolytic dissociation product $\sim 40 \mathrm{kcal} \mathrm{mol}^{-1}$ above the singlet equilibrium geometry. Thermal dissociation barriers of $\sim 30 \mathrm{kcal} \mathrm{mol}^{-1}$ were calculated from the triplet equilibrium geometries, consistent with a previous study. ${ }^{16}$ Given the large differences in BDEs between DFT and CASSCF/QD-NEVPT2 observed previously for $\mathbf{1 B},{ }^{27}$ we have also evaluated the BDEs using different levels of theory. Referencing to the experimental energy of the ${ }^{3}(d-d)$ state found by Doyle et al. $\left(12 \mathrm{kcal} \mathrm{mol}^{-1}\right),{ }^{16}$ we find BDEs of $\sim 40 \mathrm{kcal} \mathrm{mol}^{-1}$ (SCS-MP2/QZ), 41 kcal mol${ }^{-1}$ (DLPNO-CCSD(T)/QZ), and 76 kcal mol-1 (CASSCF/QD-NEVPT2; 10e, 8o) (Tables S4-5), suggesting that the DFT BDE of $\sim 30 \mathrm{kcal} \mathrm{mol}^{-1}$ represents the lower limit for thermally-driven, excited state $\mathrm{Ni}(\mathrm{II})-\mathrm{C}$ bond homolysis from the triplet ligand field equilibrium geometry. These 
calculated barriers are all significantly higher than the experimental value of $\sim 5 \mathrm{kcal} \mathrm{mol}^{-1}$ demonstrated above. Therefore, we again find that thermal dissociation from the lowest energy triplet ligand field state is not consistent with the experimental data provided here and, thus, is not a viable mechanism for excited state $\mathrm{Ni}(\mathrm{II})-\mathrm{C}$ bond homolysis.

Instead of thermally-driven excited state $\mathrm{Ni}(\mathrm{II})-\mathrm{C}$ bond homolysis from ligand field states, we propose that the mechanism of bond homolysis exploits excited state triplet repulsive aryl-to-Ni LMCT PESs (outlined in Figure 12). Critically, in these scenarios, the transfer of an electron between the bonding and antibonding $\mathrm{d}\left(\mathrm{x}^{2}-\mathrm{y}^{2}\right) / \mathrm{C}\left(\mathrm{sp}^{2}\right)$ orbitals significantly lowers the overall bond order, facilitating bond rupture. We have found two pathways utilizing either ${ }^{1}(\mathrm{~d}-\mathrm{d})$ (blue panel in Figure 12) or ${ }^{1}$ MLCT (orange panel in Figure 12) transitions as initial entrance to the excited state mechanism. In both cases, these initial excitations are followed by intersystem crossing (ISC) and formation of an aryl-to-Ni ${ }^{3} \mathrm{LMCT}$ state. Accordingly, two principally different triplet repulsive surfaces are viable for homolysis: a 'one-photon, one-electron' excited state ${ }^{3}\left[\mathrm{~d}\left(\mathrm{x}^{2}-\mathrm{y}^{2}\right) / \mathrm{C}\left(\mathrm{sp}^{2}\right) \rightarrow\right.$ $\left.\mathrm{d}\left(\mathrm{x}^{2}-\mathrm{y}^{2}\right) / \mathrm{C}\left(\mathrm{sp}^{2}\right)^{*}\right]$ and a 'one-photon, two-electron' excited state ${ }^{3}\left[\mathrm{~d}\left(\mathrm{x}^{2}-\mathrm{y}^{2}\right) / \mathrm{C}\left(\mathrm{sp}^{2}\right)+\mathrm{d}(\mathrm{yz}) \rightarrow\right.$ $\left.\mathrm{d}\left(\mathrm{x}^{2}-\mathrm{y}^{2}\right) / \mathrm{C}\left(\mathrm{sp}^{2}\right)^{*}+\pi^{*}(1)\right]$ (green and red surfaces in Figure 12 (right), respectively). This former pathway expands our initially delineated mechanism in reference 24 , wherein the probability for population of the ${ }^{1}(\mathrm{~d}-\mathrm{d})$ excited states versus the ${ }^{1}$ MLCT upon irradiation would determine the excited-state surface mediating homolysis. Indeed, it is likely this 'one-photon, one-electron' repulsive surface that facilitates $\mathrm{Ni}(\mathrm{II})-\mathrm{C}$ bond homolysis in the $\mathrm{Ni}$ (TMEDA) aryl halide complexes, as described in Section 2.1.3 above. 

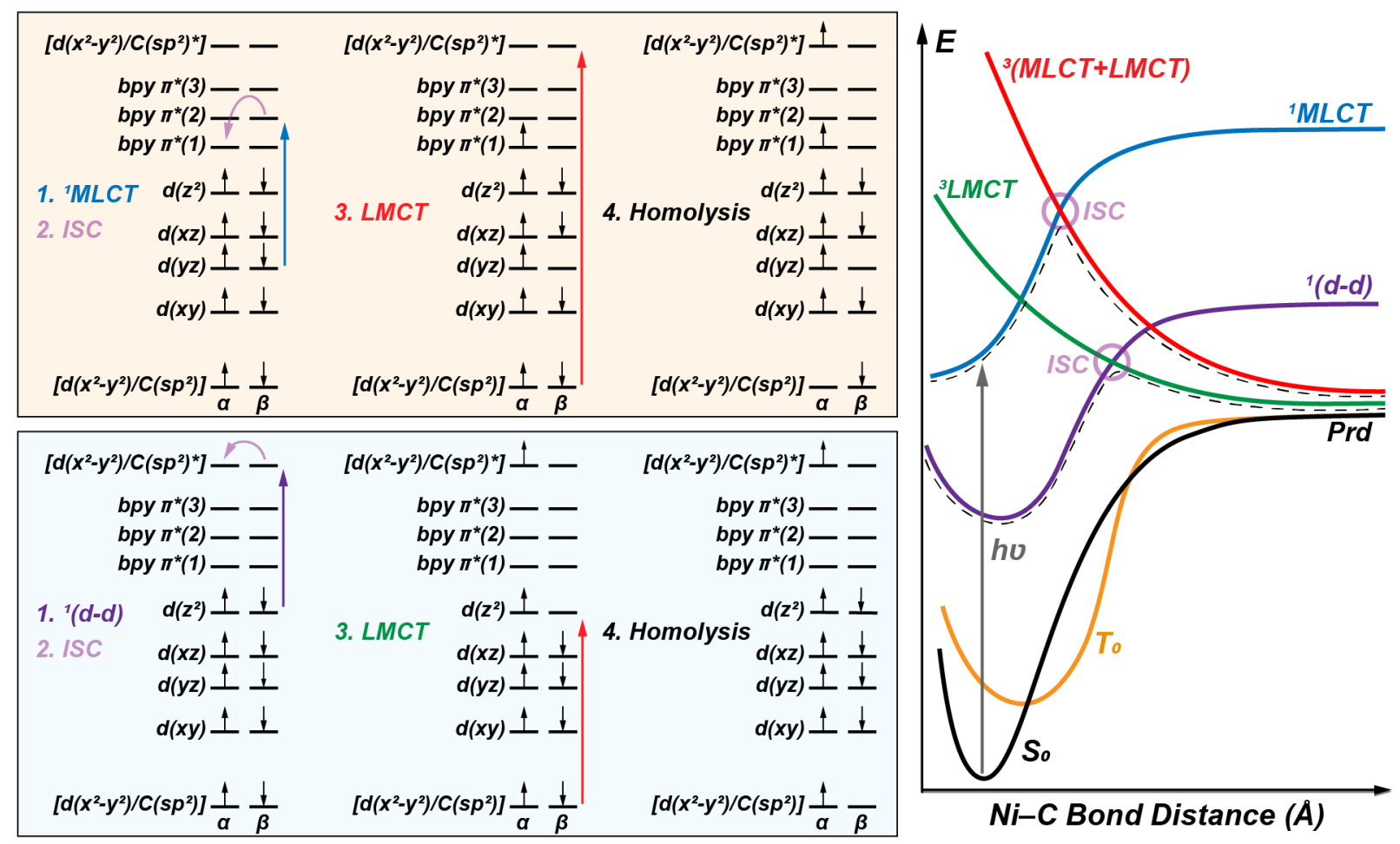

Figure 12. Two plausible excited state mechanisms of $\mathrm{Ni}(\mathrm{II})-\mathrm{C}$ bond homolysis are shown. Initial ${ }^{1}(\mathrm{~d}-\mathrm{d})$ or ${ }^{1}$ MLCT excitation (blue or orange boxes, respectively) is followed by ISC and ${ }^{3}$ LMCT formation. On the right, this surface hopping mechanism is exemplified with the shaded purple circles connecting the ${ }^{1}(\mathrm{~d}-\mathrm{d})$ excited-state surface (purple line) to the one-electron triplet repulsive ${ }^{3} \mathrm{LMCT}$ surface (green line), or ${ }^{1} \mathrm{MLCT}$ excited-state surface (blue line) to the two-electron triplet repulsive ${ }^{3}(\mathrm{MLCT}+\mathrm{LMCT})$ surface (red line). The corresponding plots computed at the TD-DFT and CASSCF/QD-NEVPT2 levels are provided in Figures S59-60. Exchange splitting between $\alpha$ and $\beta$ orbitals is neglected for clarity.

From the singlet ground state, the standard TD-DFT approach (i.e., single-electron excitations) cannot access the two-electron nature of the red surface in Figure 12 (right). Also, the spin-flipped $\alpha$-to- $\beta$ excitations (needed for description of the green surface in Figure 12, right) are only available from the singlet ground state using the restricted Kohn-Sham orbitals, which are 
inadequate for producing the accurate excited state charge transfer states, especially for out-ofequilibrium geometries with increased charge separation. Nevertheless, we were able to identify both of these triplet repulsive PESs by using TD-DFT from the high-spin $(\mathrm{S}=1)$ triplet reference state (i.e., the electronic configuration of the middle structure in the blue panel of Figure 12). From this configuration, the one-electron or two-electron triplet repulsive surfaces can be obtained via $\beta$-to- $\beta\left[\mathrm{d}\left(\mathrm{x}^{2}-\mathrm{y}^{2}\right) / \mathrm{C}\left(\mathrm{sp}^{2}\right) \rightarrow \mathrm{d}\left(\mathrm{z}^{2}\right)\right]$ or $\left[\mathrm{d}\left(\mathrm{x}^{2}-\mathrm{y}^{2}\right) / \mathrm{C}\left(\mathrm{sp}^{2}\right) \rightarrow\right.$ bpy $\left.\pi^{*}(1)\right]$ excitations. However, we note that, due to the triplet reference state containing the singly-occupied $\mathrm{Ni} d\left(\mathrm{z}^{2}\right)$ orbital configuration, our description of the ${ }^{3} \mathrm{MLCT}$ surfaces and two-electron triplet repulsive surface is restricted to those with $\left[\mathrm{Ni} \mathrm{d}\left(\mathrm{z}^{2}\right) \rightarrow\right.$ bpy $\left.\pi^{*}\right]$ MLCT transitions. Detailed discussion on the limitations of this approach is given in Supporting Information Section S2.2.

Despite these limitations, we were able to obtain an excellent energetic correlation between the 'one-photon, two-electron' triplet repulsive surface at the equilibrium geometry and both the experimental $\ln \left(k_{\mathrm{obs}, 1}\right)$ and Hammett $\sigma$ parameters (Figure S57-58), suggesting that this surface (or an analogous surface with another singly-occupied $\mathrm{Ni} \mathrm{d}$ orbital) is involved in the mechanism of excited state bond homolysis. In contrast, a significantly poorer correlation was found for the energy of the 'one-photon, one-electron' ${ }^{3}\left[\mathrm{~d}\left(\mathrm{x}^{2}-\mathrm{y}^{2}\right) / \mathrm{C}\left(\mathrm{sp}^{2}\right) \rightarrow \mathrm{d}\left(\mathrm{x}^{2}-\mathrm{y}^{2}\right) / \mathrm{C}\left(\mathrm{sp}^{2}\right)^{*}\right]$ repulsive surface (Figure S57). Furthermore, when considering that the calculated ${ }^{1 / 3}(\mathrm{~d}-\mathrm{d})$ transitions are near or below the minimum excitation-energy threshold obtained from the wavelength-dependent experiments in Figure 10, it appears that the one-electron triplet repulsive surface is not likely operative for the excited state $\mathrm{Ni}(\mathrm{II})-\mathrm{C}$ bond homolysis in $\mathbf{1 A - 5 D}$.

The activation energies derived from the high-energy ${ }^{1} \mathrm{MLCT}$ excited states (as defined by the crossing of the MLCT/triplet repulsive surface and the Frank Condon point of the MLCT state) agree qualitatively well with the activation enthalpies of $\Delta \mathrm{H}^{\ddagger}=4.4 \pm 0.6 \mathrm{kcal} \mathrm{mol}^{-1}$ and $2.1 \pm 0.3$ 
$\mathrm{kcal} \mathrm{mol}^{-1}$ measured for $\mathbf{1 B}$ and $\mathbf{1 B}-\mathbf{B r}$ (Figure 13). The best fit between the calculated activation energies and the experimental $\ln \left(k_{\mathrm{obs}, 1}\right)$ was observed for the ${ }^{1} \mathrm{MLCT}\left[\mathrm{d}(\mathrm{yz}) \rightarrow \pi^{*}(2)\right]$ excited surface hopping to the two-electron repulsive surface, ${ }^{3}\left[\mathrm{~d}\left(\mathrm{x}^{2}-\mathrm{y}^{2}\right) / \mathrm{C}\left(\mathrm{sp}^{2}\right)+\mathrm{d}\left(\mathrm{z}^{2}\right) \rightarrow \mathrm{d}\left(\mathrm{x}^{2}-\mathrm{y}^{2}\right) / \mathrm{C}\left(\mathrm{sp}^{2}\right)^{*}\right.$ $\left.+\pi^{*}(1)\right]$ (Figure 13). It should also be noted that the MLCT transitions from the donor $\mathrm{d}(\mathrm{yz})$ orbitals correspond to the absorption bands with greatest oscillator strengths, making the $[\mathrm{d}(\mathrm{yz}) \rightarrow$ $\left.\pi^{*}(2)\right]$ surface most likely to be populated from initial photon absorption. However, due to the aforementioned limitations of the TD-DFT approach (Section S2.2), we cannot exclude an equal or better correlation for the same pathway utilizing another ${ }^{3}(\mathrm{MLCT}+\mathrm{LMCT})$ excited state instead.
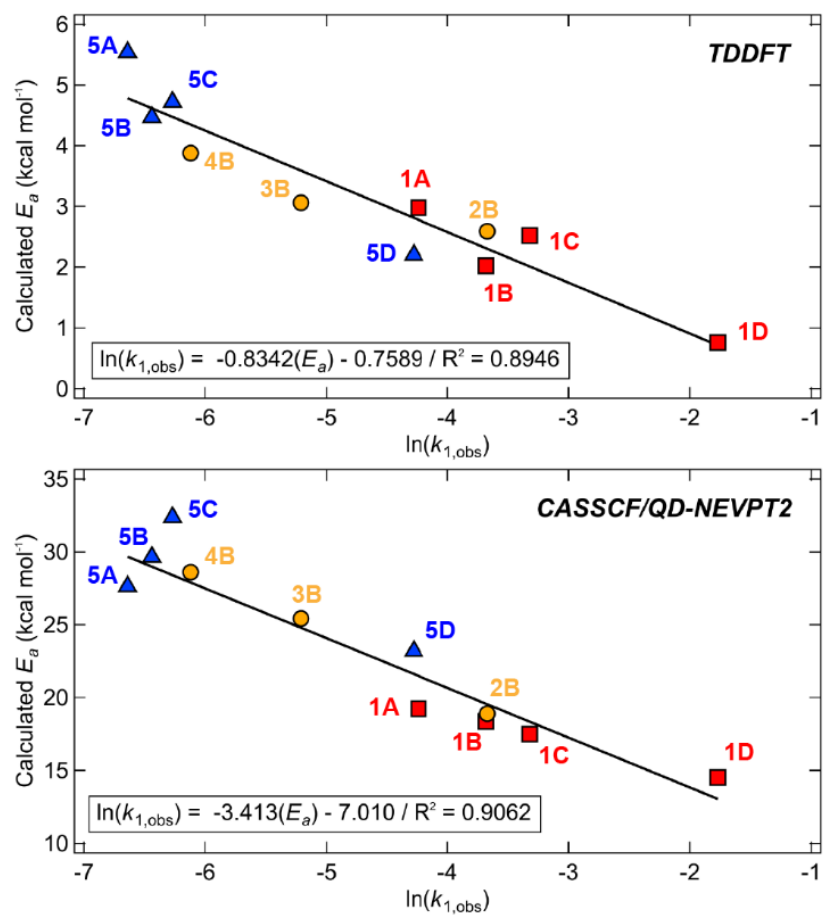

Figure 13. Computed excited state activation energies (TD-DFT, top; CASSCF/QD-NEVPT2, bottom) for 1A-5D plotted against experimental $\ln \left(k_{\mathrm{obs}, 1}\right)$ obtained using $390 \mathrm{~nm}$ excitation. Note that for $\mathbf{1 A}, k_{1, \text { obs }}$ is approximated by $k_{2, \text { obs. }}$. The activation energies are estimated from the surface crossing between the high-energy ${ }^{1} \operatorname{MLCT}\left[\mathrm{d}(\mathrm{yz}) \rightarrow \pi^{*}(2)\right]$ PES and the 'one-photon, two- 
electron' triplet repulsive surface, ${ }^{3}(\mathrm{MLCT}+\mathrm{LMCT})$ (more details can be found in Supporting Information Section S2.2; see Figure S57 for an analogous plot with the 'one-photon, one-electron' triplet repulsive surface). Additionally, we have found an activation energy of $\sim 2.2 \mathrm{kcal} \mathrm{mol}^{-1}$ for 1B-Br complex, which is in an excellent agreement with the experimental $\Delta \mathrm{H}^{\ddagger}$.

The CASSCF/QD-NEVPT2 computations provide the same photolysis mechanism for 1A-5D as that obtained from TD-DFT (Figure 12, left). However, the predicted activation energy is increased by $\sim 20-25 \mathrm{kcal} \mathrm{mol}^{-1}$ (Figure 13). This increase is likely the result of the higher Ni(II)C BDEs found by CASSCF/QD-NEVPT2, as raising the overall BDE also increases the energies of the crossing point between the initial ${ }^{1} \mathrm{MLCT}$ and the repulsive two-electron excited state surfaces. As discussed in detail in Supporting Information Section S2.2, we believe the higher BDEs for these calculations originate from a potentially incomplete description of the CASSCF reference wave function. In particular, we observe the absence of the state that would be dominated by the $\left[\mathrm{d}\left(\mathrm{x}^{2}-\mathrm{y}^{2}\right) / \mathrm{C}\left(\mathrm{sp}^{2}\right) \rightarrow \mathrm{d}\left(\mathrm{x}^{2}-\mathrm{y}^{2}\right) / \mathrm{C}\left(\mathrm{sp}^{2}\right)^{*}\right]$ configuration in the reference CASSCF, even after increasing the number of triplet states in the calculation to 100 . We note that this state is present in up to $\sim 15 \%$ in the CI vector composition of the ground singlet and triplet states, and it also mixes into many of the higher-energy states; however, the total weight does not exceed $\sim 10-40 \%$ in singlets and $\sim 0-30 \%$ in triplets over all compounds 1A-5D in calculations with 15 singlets and 25 triplets. From the initial ${ }^{1}$ MLCT $\left[\mathrm{d}(\mathrm{yz}) \rightarrow \pi^{*}(2)\right]$ excitation, we have evaluated the activation energies for this surface crossing from all of the accessible ${ }^{3}$ (MLCT+LMCT) repulsive states. Although the correlation is satisfactory with the same ${ }^{3}\left[\mathrm{~d}\left(\mathrm{x}^{2}-\mathrm{y}^{2}\right) / \mathrm{C}\left(\mathrm{sp}^{2}\right)+\mathrm{d}\left(\mathrm{z}^{2}\right)\right.$ $\left.\rightarrow \mathrm{d}\left(\mathrm{x}^{2}-\mathrm{y}^{2}\right) / \mathrm{C}\left(\mathrm{sp}^{2}\right)^{*}+\pi^{*}(1)\right]$ surface as explored by TD-DFT (with $\mathrm{R}^{2}=0.79$ ), an even better 
correlation was observed for surface hopping to the ${ }^{3}\left[\mathrm{~d}\left(\mathrm{x}^{2}-\mathrm{y}^{2}\right) / \mathrm{C}\left(\mathrm{sp}^{2}\right)+\mathrm{d}(\mathrm{yz}) \rightarrow \mathrm{d}\left(\mathrm{x}^{2}-\right.\right.$ $\left.\left.\mathrm{y}^{2}\right) / \mathrm{C}\left(\mathrm{sp}^{2}\right)^{*}+\pi^{*}(1)\right]$, characterized by $\mathrm{R}^{2}=0.91$ (Figure 13, bottom).

Overall, both TD-DFT and CASSCF/QD-NEVPT2 methods predict analogous photolysis mechanisms that exploit triplet repulsive 'one-photon, two-electron' excited state PESs, and the calculations further capture the critical aspects that lead to geometric and electronic structural control over the excited state PES manifold that ultimately governs the photochemical behavior. However, each method is associated with its own limitations, precluding a definitive assignment of which ${ }^{1 / 3} \mathrm{MLCT}$ is initially operative or at which stage ISC occurs (i.e., before or after the surface hopping between MLCT and MLCT+LMCT surfaces). We also speculate that this mechanism may not be identical for all Ni complexes used in photoredox catalysis. Additional possibilities, including the 'one-photon, one-electron' ${ }^{1 / 3}(\mathrm{~d}-\mathrm{d}) \rightarrow{ }^{1} \mathrm{LMCT}$ pathway, might be operative depending on the energetics of the individual excited states, the probability of the initial lightinduced transitions, and/or the probability of the surface hopping to the triplet repulsive PESs.

\section{Discussion}

Light-induced homolysis provides a powerful means to activate ligand-metal bonds for the generation of reactive radical species involved in targeted catalytic bond transformations. $5,45,46$ Defining the photophysical processes underlying the mechanisms of light-induced homolysis will therefore aid chemists in elucidating the role(s) of photo-generated intermediates in currently established photoredox catalytic cycles, as well as further guide the development of novel bondformation reactions in organic chemistry. Here we have provided new combined experimental and computational insights that have aided in the elucidation of the mechanism of excited state Ni(II)C bond homolysis in commonly employed Ni(II)-bpy aryl halide photoredox catalysts. In 
particular, rates of excited state homolysis depend on temperature (Figure 9) and the wavelength of light excitation (Figure 10). From these observations, we conclude that there exists an energy barrier between the light absorbing and homolytically dissociative excited states. For $\mathbf{1 B}, \Delta \mathrm{H}^{\ddagger}=$ $4.4 \pm 0.6 \mathrm{kcal} \mathrm{mol}^{-1}$ using $390 \mathrm{~nm}$ excitation. Note $\Delta \mathrm{H}^{\ddagger}$ is the energy parameter that is most relevant for comparisons to calculated excited state PESs. From the wavelength dependence on the rates, it is also clear that the lower energy ${ }^{1}$ MLCTs $(<\sim 525 \mathrm{~nm}$ or $\sim 55 \mathrm{kcal} / \mathrm{mol})$ are not productive for excited state homolysis. Rather, higher energy excitation is required. Overall, these observations are not consistent with thermally-driven $\mathrm{Ni}(\mathrm{II})-\mathrm{C}$ bond homolysis from excited ligand field states. We further note that similar wavelength dependence trends have been demonstrated for $\mathrm{Ni}(\mathrm{II})-$ bpy mediated $\mathrm{C}-\mathrm{O}$ cross-coupling yields, directly implicating these high energy ${ }^{1} \mathrm{MLCT}$ states in photoredox catalysis. ${ }^{22}$

In addition to the temperature and wavelength dependence, we have found that the rates of homolysis in Ni(II)-bpy aryl halide complexes are also sensitive to variations in both the solvent and the nature of all three ligands. For example, the rates of excited state $\mathrm{Ni}(\mathrm{II})-\mathrm{C}$ bond homolysis for $\mathbf{1 B}$ and $\mathbf{1 B}-\mathbf{B r}$ are slower in toluene and DMF (Figure S42-45) relative to THF, suggesting a solvent influence on the excited state PESs. Solvent dependence has been observed for other lightinduced homolysis reactions that feature activation energies, and similar arguments regarding perturbations to the barrier have been made. ${ }^{47,48}$ Furthermore, exchanging chloride with bromide (1B versus 1B-Br) increases the observed rate of homolysis from $2.5 \pm 0.2$ to $6.9 \pm 0.4 \times 10^{-2} \mathrm{~min}^{-}$ 1. The calculated barriers and excited state PESs for these two compounds are similar (Figure S61). However, changing $\mathrm{Cl}$ to $\mathrm{Br}$ increases the ligand-based spin-orbit coupling constant. ${ }^{49}$ This increased spin-orbit coupling may increase the rate of surface crossing and suggests spin-vibronic effects may be important to consider (vide infra)..$^{50-52}$ 
Variation of the bpy ligand (columns in Figure 2) modifies the MLCT $\lambda_{\max }$ (Figure 3B) and the rate of homolysis at a given excitation wavelength; there is in fact a linear correlation between the normalized logarithm of the rate and the $\sigma_{\mathrm{p}}$ of the bpy substituent (Figure 7). Increased electron withdrawing strength of the bpy lowers the energies of the MLCT excited state PES manifold (e.g., the MLCT of $1 \mathrm{D}$ is $8.1 \mathrm{kcal} \mathrm{mol}^{-1}$ lower relative to $\mathbf{1 A}$, see Figure 14A). If the MLCT surface was the only excited state PES involved in the bond rupture mechanism, one would expect an increased barrier and an accordingly slower rate for homolysis in 1D than for 1A. However, when considering the barrier as governed by the crossing point between the MLCT and ${ }^{3}(\mathrm{MLCT}+\mathrm{LMCT})$ states, the correct rate trend is recovered. Increasing the electron withdrawing strength of the bpy enables more facile aryl-to-Ni(III) charge transfer, lowering the LMCT energies. Furthermore, from the Hammett trends/slopes (Figure 7), we see a greater impact on the rate when modulating the aryl substituent (i.e., the LMCT component) versus the bpy substituent. Thus, while the energetic shifts of the ${ }^{1}$ MLCT and ${ }^{3}(\mathrm{MLCT}+\mathrm{LMCT})$ PESs are of the same sign, they shift at different rates as a function of ligand perturbation. The ligand-based effects on the ${ }^{3}$ (MLCT+LMCT) repulsive excited state outweigh the drop in the initial MLCT energy. Ultimately, these effects result in a lower barrier for homolysis (e.g., 1D has a barrier $1.4 \mathrm{kcal}$ $\mathrm{mol}^{-1}$ lower than that for $\mathbf{1 A}$, Figure 14B) and, thus, a faster rate. The ligand-based perturbations to the excited state PESs described in Figure 14C demonstrate that the coupled changes to the overall excited state PES manifold, including surface intersections and barriers, govern the rates of $\mathrm{Ni}(\mathrm{II})-\mathrm{C}$ bond homolysis. 

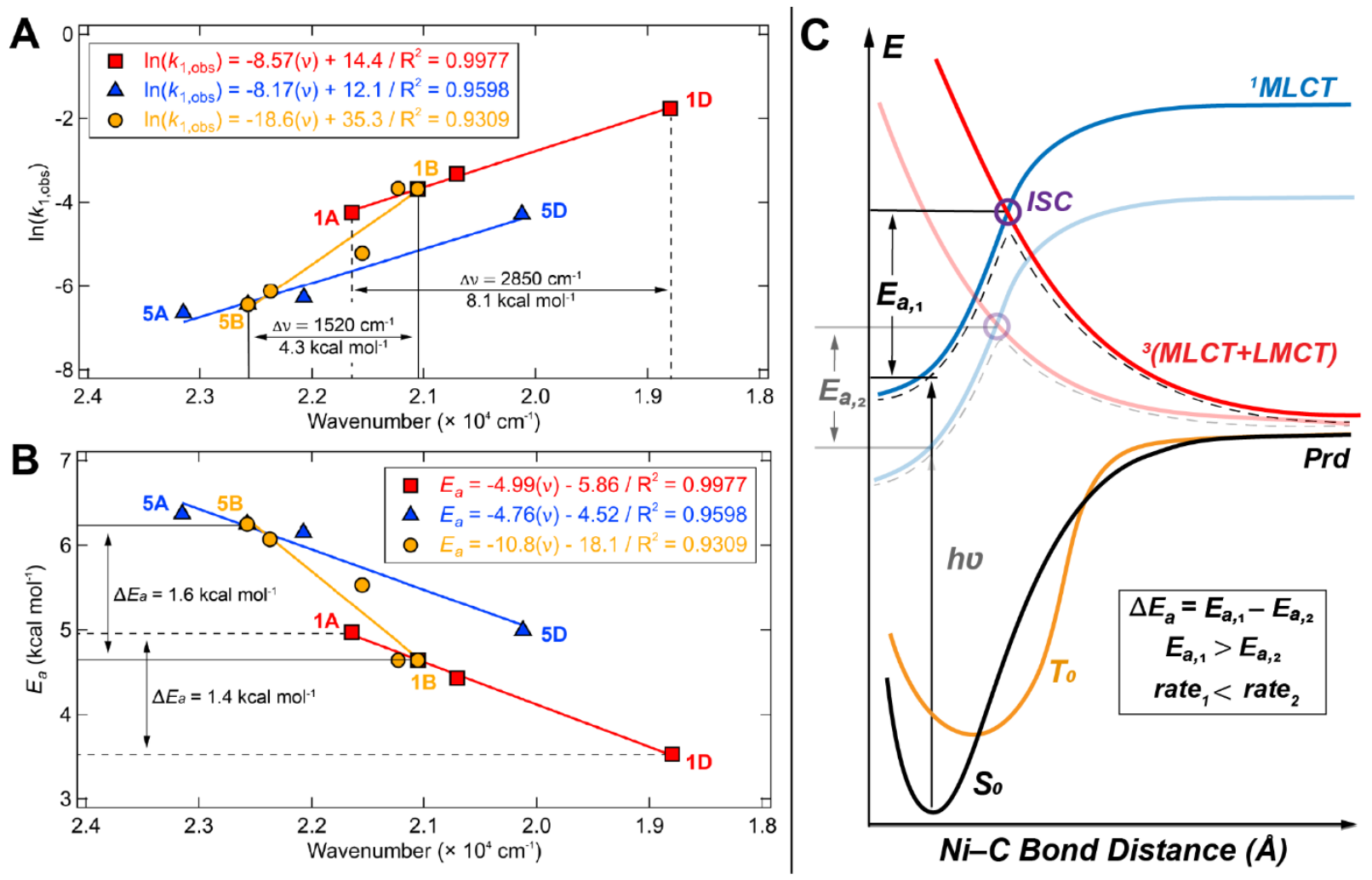

Ni-C Bond Distance $(A)$

Figure 14. Comparison between the change in energy of the MLCT $\lambda_{\max }$ and (A) the experimental $\ln \left(k_{\text {obs, } 1}\right)$ obtained with $390 \mathrm{~nm}$ excitation and (B) the energetic barrier for photolysis for 1A-1D and 1B-5B. Barriers are estimated using the Arrhenius equation (assuming a uniform preexponential factor) and are normalized to the experimental value obtained for 1B. (C) PES diagram illustrating how the barrier for photolysis is dependent on both the ${ }^{1}$ MLCT and repulsive ${ }^{3}(\mathrm{MLCT}+\mathrm{LMCT})$ surfaces. Full detailed PESs for 1A-5D are given in Figures S59-60.

Electronic structure calculations have provided further insights into these experimental observations, successfully correlating the calculated PES features to the experimental rates by capturing the critical aspects that lead to geometric and electronic structure control over the excited state PES manifolds (Figure 11). Also, both TD-DFT and CASSCF/QD-NEVPT2 methods predict analogous mechanisms that exploit 'one-photon, two-electron' repulsive ${ }^{3}$ (MLCT+LMCT) excited 
state PESs. In particular, Figure 13 demonstrates a strong correlation between the computed excited state activation energies and the experimental $\ln \left(k_{\mathrm{obs}, 1}\right)$ obtained using $390 \mathrm{~nm}$ excitation. The activation energies are predicted to arise from the surface crossing between the high-energy ${ }^{1} \operatorname{MLCT}\left[\mathrm{d}(\mathrm{yz}) \rightarrow \pi^{*}(2)\right]$ PES and the two-electron triplet repulsive surface, ${ }^{3}$ (MLCT+LMCT). Thus, the calculations are consistent with the overall experimental data and mechanism presented in Figure 14C.

Further comment on the specific mode of entry into the repulsive ${ }^{3}(\mathrm{MLCT}+\mathrm{LMCT})$ state is warranted. Given that the UV-vis electronic absorption spectra of Ni(II)-bpy compounds exhibit dominantly MLCT intensity, there is a minimum energy threshold for homolysis, and the calculated ligand field transitions are lower than the higher energy, photochemically active excited states, we posit that MLCT surfaces provide an entry into the ${ }^{3}(\mathrm{MLCT}+\mathrm{LMCT})$ state. However, we do not know if intersystem crossing occurs between ${ }^{1,3}$ MLCT states or the ${ }^{3}$ (MLCT+LMCT) states.

It may also be the case that vibronic coupling between charge transfer and ligand field states may be an important component of the mechanism (vide infra) ${ }^{52}$ Therefore, experimental determination of the energies of the ligand field transitions across these Ni(II)-bpy aryl halide complexes would be informative. If the ${ }^{1}(d-d)$ transitions are indeed experimentally obscured by the dominant, photochemically active MLCT intensity, electronic absorption will not be appropriate. Due to the $C$-term intensity mechanism, low temperature optical magnetic circular dichroism (MCD) would be ideal for this. However, the diamagnetic ground states of these complexes will also likely complicate ligand field assignments. As an alternative, $2 \mathrm{p} 3 \mathrm{~d}$ resonant inelastic X-ray scattering (RIXS) is a less commonly employed, but powerful, methodology to obtain spectroscopic insights into the spin-allowed and -forbidden ligand field excited state 
manifolds. ${ }^{53-58}$ This represents a potential approach to observe the ligand field excited state manifold in the presence of charge transfer bands.

As elucidated in Section 2.1.4, light-induced homolysis results in the production of an additional visible-light absorbing species. Based on the correlation between the UV-vis spectrum of the intermediate formed from 1B-Br via photolysis to that identified recently by Bird et al., ${ }^{37}$ we tentatively assign this species as a three-coordinate, formal $\mathrm{Ni}(\mathrm{I})(\mathrm{bpy})(\mathrm{Br})$ complex. While further study of this intermediate is outside the scope of this study, it is worth noting that, under controlled air- and moisture-free conditions, excited state homolysis provides a means to generate and isolate putative reactive intermediates for detailed studies of their spectroscopic properties and reactivity patterns. Furthermore, the rate of formation of these intermediates is tunable via structural and electronic control over key PESs, affording chemists new photon-driven synthetic possibilities in photoredox catalysis. ${ }^{59}$

Finally, it is instructive to note that findings reported here resemble results from detailed photochemical investigations of $\left[\operatorname{Re}(\mathrm{R})(\mathrm{CO})_{3}(\alpha\right.$-diimine $\left.)\right]$ complexes $(\mathrm{R}=\mathrm{Me}, \mathrm{Et}, \mathrm{Bz}){ }^{47,48,60-66}$ For these complexes, it was found that the excited state Re-R bond homolysis is a result of the formation of a repulsive $\sigma \pi^{*}$ excited state. This dissociative state is not accessible via direct excitation, but is instead accessed from excitation of the ${ }^{1}$ MLCT state (one electron on the $\alpha-$ diamine followed by Re-R LMCT). However, there are significant variations in excited state dynamics on varying the $\mathrm{R}$ group. For Et and $\mathrm{Bz}$, the quantum yield is near unity and excited state homolysis does not depend on temperature or wavelength of excitation. Their $\sigma \pi^{*}$ excited states are populated in $<20 \mathrm{ps}$, are relatively slowly dissociating (weakly bound), and are therefore detectable using transient spectroscopies. These $\sigma \pi^{*}$ excited states are located energetically below the ${ }^{1}$ MLCT state, with the intersection/hopping point being close to the minimum of the latter PES. 
On the other hand, excited state homolysis in the $\operatorname{Re}(\mathrm{Me})(\mathrm{CO})_{3}(\alpha$-diimine) complexes (i.e., $\mathrm{R}=$ Me instead of Et/Bz) occurs on the sub-picosecond time scale with a small quantum yield and is dependent on temperature and excitation wavelength, with activation energies between $\sim 1.8-5.5$ kcal mol ${ }^{-1}$ using $458-502 \mathrm{~nm}$ excitation $\left(\sim 62.4-57.0 \mathrm{kcal} \mathrm{mol}^{-1}\right) .{ }^{48}$ These excited state barriers are in the range of those determined for $\mathrm{Ni}(\mathrm{II})$-bpy aryl halide complexes studied here and are indicative of a dissociative excited state that is higher in energy than the ${ }^{1}$ MLCT excited state, necessitating a barrier and surface crossing (Figure 14A-B). It was further noted previously that enhanced quantum yields correlated with increasing energy of excitation; this behavior mirrors the rate accelerations we observed herein upon increased excitation energy. For the Re complexes, this was interpreted as arising from excitation into higher energy vibronic levels of the ${ }^{1} \mathrm{MLCT}$ state, which promotes the ${ }^{1}$ MLCT $\rightarrow \sigma \pi^{*}$ surface hopping. ${ }^{47,64}$ Based on these similarities, in particular the increased homolysis rates with increasing energy of excitation into the higher energy MLCT transitions (Figure 10), we hypothesize that the mechanism of excited state homolysis in $\mathrm{Ni}(\mathrm{II})$-bpy aryl halide complexes may indeed feature a similar vibronically-mediated component, wherein the optically excited ${ }^{1} \mathrm{MLCT}$ is vibronically coupled to dissociative ${ }^{3}$ (MLCT+LMCT) states, or even potentially to weakly absorbing ligand field excited states.

Ni(II)-bpy aryl halide complexes feature a high density of excited states (Figure S59, Tables S8-9), many vibrational degrees of freedom, and large spin-orbit coupling. The combination of these factors can complicate mechanistic analyses that feature discrete processes of vibrational relaxation, internal conversion, and intersystem crossing, especially when they occur on the timescale of molecular vibrations (i.e., sub-picosecond timescale). ${ }^{52,67}$ Thus, the ultrafast spectroscopic characterization of the homolytically active state in $\mathrm{Ni}(\mathrm{II})$-bpy aryl halide complexes may be hampered by the nature of the excited state homolysis mechanism. That is, the 
spectral dynamics will be dominated by MLCT and ligand field states, and there may be little to no dynamics detectable for the repulsive ${ }^{3}(\mathrm{MLCT}+\mathrm{LMCT})$ surfaces proposed here, unless they can be accessed in sufficient amounts, perhaps with high energy excitation. Additionally, it may be that the TD-DFT and multiconfigurational/multireference mechanistic pictures provided by the calculated PESs need to be further supplemented to account for more complex aspects of spinvibronic coupling. ${ }^{52}$ Further experimental characterization of aspects such as the specific state that provides entry to the repulsive ${ }^{3}(\mathrm{MLCT}+\mathrm{LMCT})$ states, as well as more detailed experimental characterization of potential spin-vibronic coupling effects will be useful for better understanding how they manifest in the mechanism of excited state bond homolysis.

\section{Conclusions}

In summary, we have demonstrated that rates of excited state $\mathrm{Ni}(\mathrm{II})-\mathrm{C}$ bond homolysis are temperature- and wavelength-dependent. Both of these experimental observations point to a thermal barrier involved in the photophysical mechanism. The barrier is moderate and inconsistent with thermally-driven homolysis from a low energy ligand field excited state. In addition, we have demonstrated a linear correlation between bpy and aryl perturbations and the observed rates of homolysis using a constant energy of irradiation. In this way, pinning the excitation wavelength reveals the ligand-induced electronic perturbations to the energetic barrier for $\mathrm{Ni}(\mathrm{II})-\mathrm{C}$ bond homolysis by controlling the key excited state MLCT/LMCT surfaces. In accordance with this, electronic structure calculations predict a mechanism that exploits 'one-photon, two-electron' repulsive ${ }^{3}(\mathrm{MLCT}+\mathrm{LMCT})$ excited state PESs and reveal a strong correlation between the computed excited state activation energies and the experimental $\ln \left(k_{\mathrm{obs}, 1}\right)$ obtained using $390 \mathrm{~nm}$ excitation. The activation energies are predicted to arise from the surface crossing between the 
high-energy ${ }^{1}$ MLCT $\left[\mathrm{d}(\mathrm{yz}) \rightarrow \pi^{*}(2)\right]$ and the two-electron triplet repulsive surfaces, highlighting the specific excited state PESs that contribute to $\mathrm{Ni}(\mathrm{II})$-bpy-mediated photoredox catalysis. This study provides insights into the electronic structural control over light-induced homolysis and, thus, guides the use of photonic energy as a sustainable alternative to coupling catalysis as carried out by precious metals.

\section{Supporting Information}

The Supporting Information is available free of charge on the ACS Publications website at DOI: . Experimental and computational methods, UV-vis/photochemical data, X-ray crystallography, NMR spectra, calculated spectra/properties, global analysis modeling, and additional comments.

\section{Acknowledgments}

D.A.C. is a National Science Foundation Graduate Research Fellow (DGE-1745301) and is supported by a National Academies of Science, Engineering, and Medicine Ford Foundation Predoctoral Fellowship. B.S. acknowledges funding through a Southern California Edison WAVE fellowship at Caltech. N.P.K. acknowledges support from the Hertz Fellowship and from the National Science Foundation Graduate Research Fellowship under Grant No. DGE-1745301. This project has received funding from the European Union's Horizon 2020 research and innovation programme under the Marie Sklodowska-Curie grant agreement No. 883987 (D.B.). Support has been provided by the National Institutes of Health (National Institute of General Medical Sciences, R35-GM142595). We also acknowledge M. K. Takase in the Beckman Institute X-ray crystallography facility. The computations presented here were conducted in the Resnick High 
Performance Computing Center, a facility supported by Resnick Sustainability Institute at the California Institute of Technology. 


\section{References}

(1) Nicewicz, D. A.; MacMillan, D. W. C. Merging Photoredox Catalysis with Organocatalysis: The Direct Asymmetric Alkylation of Aldehydes. Science 2008, 322 (5898), 77-80. https://doi.org/10.1126/science.1161976.

(2) Shaw, M. H.; Twilton, J.; MacMillan, D. W. C. Photoredox Catalysis in Organic Chemistry. J. Org. Chem. 2016, 81 (16), 6898-6926. https://doi.org/10.1021/acs.joc.6b01449.

(3) Cavalcanti, L. N.; Molander, G. A. Photoredox Catalysis in Nickel-Catalyzed CrossCoupling. Top. Curr. Chem. 2016, 374 (4), 39. https://doi.org/10.1007/s41061-016-0037-z.

(4) Till, N. A.; Tian, L.; Dong, Z.; Scholes, G. D.; MacMillan, D. W. C. Mechanistic Analysis of Metallaphotoredox $\mathrm{C}-\mathrm{N}$ Coupling: Photocatalysis Initiates and Perpetuates $\mathrm{Ni}(\mathrm{I}) / \mathrm{Ni}(\mathrm{III})$ Coupling Activity. J. Am. Chem. Soc. 2020, 142 (37), 15830-15841. https://doi.org/10.1021/jacs.0c05901.

(5) Qin, Y.; Sun, R.; Gianoulis, N. P.; Nocera, D. G. Photoredox Nickel-Catalyzed C-S CrossCoupling: Mechanism, Kinetics, and Generalization. J. Am. Chem. Soc. 2021, 143 (4), 2005-2015. https://doi.org/10.1021/jacs.0c11937.

(6) Huang, L.; Ji, T.; Rueping, M. Remote Nickel-Catalyzed Cross-Coupling Arylation via Proton-Coupled Electron Transfer-Enabled C-C Bond Cleavage. J. Am. Chem. Soc. 2020, 142 (7), 3532-3539. https://doi.org/10.1021/jacs.9b12490.

(7) Ackerman, L. K. G.; Martinez Alvarado, J. I.; Doyle, A. G. Direct C-C Bond Formation from Alkanes Using Ni-Photoredox Catalysis. J. Am. Chem. Soc. 2018, 140 (43), 1405914063. https://doi.org/10.1021/jacs.8b09191.

(8) Kim, T.; McCarver, S. J.; Lee, C.; MacMillan, D. W. C. Sulfonamidation of Aryl and Heteroaryl Halides through Photosensitized Nickel Catalysis. Angew. Chem. Int. Ed. 2018, 57 (13), 3488-3492. https://doi.org/10.1002/anie.201800699.

(9) Zhang, R.; Li, G.; Wismer, M.; Vachal, P.; Colletti, S. L.; Shi, Z.-C. Profiling and Application of Photoredox $\mathrm{C}\left(\mathrm{sp}^{3}\right)-\mathrm{C}\left(\mathrm{sp}^{2}\right)$ Cross-Coupling in Medicinal Chemistry. ACS Med. Chem. Lett. 2018, 9 (7), 773-777. https://doi.org/10.1021/acsmedchemlett.8b00183.

(10) Schultz, D. M.; Yoon, T. P. Solar Synthesis: Prospects in Visible Light Photocatalysis. Science 2014, 343 (6174), 1239176. https://doi.org/10.1126/science.1239176.

(11) M. Arias-Rotondo, D.; K. McCusker, J. The Photophysics of Photoredox Catalysis: A Roadmap for Catalyst Design. Chem. Soc. Rev. 2016, 45 (21), 5803-5820. https://doi.org/10.1039/C6CS00526H.

(12) Larsen, C. B.; Wenger, O. S. Photoredox Catalysis with Metal Complexes Made from EarthAbundant Elements. Chem. - Eur. J. 2018, 24 (9), 2039-2058. https://doi.org/10.1002/chem.201703602.

(13) Yoon, T. P.; Ischay, M. A.; Du, J. Visible Light Photocatalysis as a Greener Approach to Photochemical Synthesis. Nat. Chem. 2010, 2 (7), 527-532. https://doi.org/10.1038/nchem.687.

(14) Chan, A. Y.; Perry, I. B.; Bissonnette, N. B.; Buksh, B. F.; Edwards, G. A.; Frye, L. I.; Garry, O. L.; Lavagnino, M. N.; Li, B. X.; Liang, Y.; Mao, E.; Millet, A.; Oakley, J. V.; Reed, N. L.; Sakai, H. A.; Seath, C. P.; MacMillan, D. W. C. Metallaphotoredox: The Merger of Photoredox and Transition Metal Catalysis. Chem. Rev. 2021. https://doi.org/10.1021/acs.chemrev.1c00383.

(15) Diccianni, J. B.; Diao, T. Mechanisms of Nickel-Catalyzed Cross-Coupling Reactions. Trends Chem. 2019, 1 (9), 830-844. https://doi.org/10.1016/j.trechm.2019.08.004. 
(16) Ting, S. I.; Garakyaraghi, S.; Taliaferro, C. M.; Shields, B. J.; Scholes, G. D.; Castellano, F. N.; Doyle, A. G. ${ }^{3}$ d-d Excited States of Ni(II) Complexes Relevant to Photoredox Catalysis: Spectroscopic Identification and Mechanistic Implications. J. Am. Chem. Soc. 2020, 142 (12), 5800-5810. https://doi.org/10.1021/jacs.0c00781.

(17) Welin, E. R.; Le, C.; Arias-Rotondo, D. M.; McCusker, J. K.; MacMillan, D. W. C. Photosensitized, Energy Transfer-Mediated Organometallic Catalysis through Electronically Excited Nickel(II). Science 2017, 355 (6323), 380-385. https://doi.org/10.1126/science.aal2490.

(18) Strieth-Kalthoff, F.; Glorius, F. Triplet Energy Transfer Photocatalysis: Unlocking the Next Level. Chem 2020, 6 (8), 1888-1903. https://doi.org/10.1016/j.chempr.2020.07.010.

(19) Sun, R.; Qin, Y.; Ruccolo, S.; Schnedermann, C.; Costentin, C.; Nocera, D. G. Elucidation of a Redox-Mediated Reaction Cycle for Nickel-Catalyzed Cross Coupling. J. Am. Chem. Soc. 2019, 141 (1), 89-93. https://doi.org/10.1021/jacs.8b11262.

(20) Yuan, M.; Song, Z.; Badir, S. O.; Molander, G. A.; Gutierrez, O. On the Nature of C( $\left.\mathrm{sp}^{3}\right)_{-}$ $\mathrm{C}\left(\mathrm{sp}^{2}\right)$ Bond Formation in Nickel-Catalyzed Tertiary Radical Cross-Couplings: A Case Study of Ni/Photoredox Catalytic Cross-Coupling of Alkyl Radicals and Aryl Halides. J. Am. Chem. Soc. 2020, 142 (15), 7225-7234. https://doi.org/10.1021/jacs.0c02355.

(21) Shields, B. J.; Kudisch, B.; Scholes, G. D.; Doyle, A. G. Long-Lived Charge-Transfer States of Nickel(II) Aryl Halide Complexes Facilitate Bimolecular Photoinduced Electron Transfer. J. Am. Chem. Soc. 2018, 140 (8), 3035-3039. https://doi.org/10.1021/jacs.7b13281.

(22) Yang, L.; Lu, H.-H.; Lai, C.-H.; Li, G.; Zhang, W.; Cao, R.; Liu, F.; Wang, C.; Xiao, J.; Xue, D. Light-Promoted Nickel Catalysis: Etherification of Aryl Electrophiles with Alcohols Catalyzed by a NiII-Aryl Complex. Angew. Chem. Int. Ed. 2020, 59 (31), 1271412719. https://doi.org/10.1002/anie.202003359.

(23) Tian, L.; Till, N. A.; Kudisch, B.; MacMillan, D. W. C.; Scholes, G. D. Transient Absorption Spectroscopy Offers Mechanistic Insights for an Iridium/Nickel-Catalyzed C-O Coupling. J. Am. Chem. Soc. 2020, 142 (10), 4555-4559. https://doi.org/10.1021/jacs.9b12835.

(24) Ma, P.; Wang, S.; Chen, H. Reactivity of Transition-Metal Complexes in Excited States: CO Bond Coupling Reductive Elimination of a Ni(II) Complex Is Elicited by the Metal-toLigand Charge Transfer State. ACS Catal. 2020, 10 (1), 1-6. https://doi.org/10.1021/acscatal.9b03827.

(25) Han, R.; Hillhouse, G. L. Carbon-Oxygen Reductive-Elimination from Nickel(II) Oxametallacycles and Factors That Control Formation of Ether, Aldehyde, Alcohol, or Ester Products. J. Am. Chem. Soc. 1997, 119 (34), 8135-8136. https://doi.org/10.1021/ja9714999.

(26) Koo, K.; Hillhouse, G. L. Carbon-Nitrogen Bond Formation by Reductive Elimination from Nickel(II) Amido Alkyl Complexes. Organometallics 1995, 14 (9), 4421-4423. https://doi.org/10.1021/om00009a054.

(27) Cagan, D. A.; Stroscio, G. D.; Cusumano, A. Q.; Hadt, R. G. Multireference Description of Nickel-Aryl Homolytic Bond Dissociation Processes in Photoredox Catalysis. J. Phys. Chem. A 2020, 124 (48), 9915-9922. https://doi.org/10.1021/acs.jpca.0c08646.

(28) Shields, J. D.; Gray, E. E.; Doyle, A. G. A Modular, Air-Stable Nickel Precatalyst. Org. Lett. 2015, 17 (9), 2166-2169. https://doi.org/10.1021/acs.orglett.5b00766.

(29) Marshall, W. J.; Grushin, V. V. Activation of Chlorobenzene with Ni(0) N,N-Chelates - A Remarkably Profound Effect of a Minuscule Change in Ligand Structure. Can. J. Chem. 2005, 83 (6-7), 640-645. https://doi.org/10.1139/v05-022. 
(30) Hansch, Corwin.; Leo, A.; Taft, R. W. A Survey of Hammett Substituent Constants and Resonance and Field Parameters. Chem. Rev. 1991, 91 (2), 165-195. https://doi.org/10.1021/cr00002a004.

(31) Sinnokrot, M. O.; Sherrill, C. D. Substituent Effects in $\Pi-\pi$ Interactions: Sandwich and TShaped Configurations. J. Am. Chem. Soc. 2004, 126 (24), 7690-7697. https://doi.org/10.1021/ja049434a.

(32) Ringer, A. L.; Sinnokrot, M. O.; Lively, R. P.; Sherrill, C. D. The Effect of Multiple Substituents on Sandwich and T-Shaped $\pi-\pi$ Interactions. Chem. - Eur. J. 2006, 12 (14), 3821-3828. https://doi.org/10.1002/chem.200501316.

(33) Gung, B. W.; Patel, M.; Xue, X. A Threshold for Charge Transfer in Aromatic Interactions? A Quantitative Study of $\pi$-Stacking Interactions. J. Org. Chem. 2005, 70 (25), 1053210537. https://doi.org/10.1021/jo051808a.

(34) Wheeler, S. E.; Houk, K. N. Substituent Effects in the Benzene Dimer Are Due to Direct Interactions of the Substituents with the Unsubstituted Benzene. J. Am. Chem. Soc. 2008, 130 (33), 10854-10855. https://doi.org/10.1021/ja802849j.

(35) Santiago, C. B.; Milo, A.; Sigman, M. S. Developing a Modern Approach To Account for Steric Effects in Hammett-Type Correlations. J. Am. Chem. Soc. 2016, 138 (40), 1342413430. https://doi.org/10.1021/jacs.6b08799.

(36) Lewis, M.; Bagwill, C.; Hardebeck, L. K. E.; Wireduaah, S. The Use of Hammett Constants to Understand the Non-Covalent Binding of Aromatics. Comput. Struct. Biotechnol.J. 2012, 1, e201204004. https://doi.org/10.5936/csbj.201204004.

(37) Till, N. A.; Oh, S.; MacMillan, D. W. C.; Bird, M. J. The Application of Pulse Radiolysis to the Study of $\mathrm{Ni}(\mathrm{I})$ Intermediates in Ni-Catalyzed Cross-Coupling Reactions. J. Am. Chem. Soc. 2021, 143 (25), 9332-9337. https://doi.org/10.1021/jacs.1c04652.

(38) Roos, B. O.; Taylor, P. R.; Sigbahn, P. E. M. A Complete Active Space SCF Method (CASSCF) Using a Density Matrix Formulated Super-CI Approach. Chem. Phys. 1980, 48 (2), 157-173. https://doi.org/10.1016/0301-0104(80)80045-0.

(39) Siegbahn, P. E. M.; Almlöf, J.; Heiberg, A.; Roos, B. O. The Complete Active Space SCF (CASSCF) Method in a Newton-Raphson Formulation with Application to the HNO Molecule. J. Chem. Phys. 1981, 74 (4), 2384-2396. https://doi.org/10.1063/1.441359.

(40) Angeli, C.; Borini, S.; Cestari, M.; Cimiraglia, R. A Quasidegenerate Formulation of the Second Order N-Electron Valence State Perturbation Theory Approach. J. Chem. Phys. 2004, 121 (9), 4043-4049. https://doi.org/10.1063/1.1778711.

(41) Lang, L.; Sivalingam, K.; Neese, F. The Combination of Multipartitioning of the Hamiltonian with Canonical Van Vleck Perturbation Theory Leads to a Hermitian Variant of Quasidegenerate N-Electron Valence Perturbation Theory. J. Chem. Phys. 2020, 152 (1), 014109. https://doi.org/10.1063/1.5133746.

(42) Becke, A. D. Density-functional Thermochemistry. III. The Role of Exact Exchange. $J$. Chem. Phys. 1993, 98 (7), 5648-5652. https://doi.org/10.1063/1.464913.

(43) Lee, C.; Yang, W.; Parr, R. G. Development of the Colle-Salvetti Correlation-Energy Formula into a Functional of the Electron Density. Phys. Rev. B 1988, 37 (2), 785-789. https://doi.org/10.1103/PhysRevB.37.785.

(44) Becke, A. D. Density-Functional Exchange-Energy Approximation with Correct Asymptotic Behavior. Phys. Rev. A 1988, 38 (6), 3098-3100. https://doi.org/10.1103/PhysRevA.38.3098. 
(45) Abderrazak, Y.; Bhattacharyya, A.; Reiser, O. Visible-Light-Induced Homolysis of EarthAbundant Metal-Substrate Complexes: A Complementary Activation Strategy in Photoredox Catalysis. Angew. Chem. Int. Ed. 2021, 60 (39), 21100-21115. https://doi.org/10.1002/anie.202100270.

(46) Hwang, S. J.; Powers, D. C.; Maher, A. G.; Anderson, B. L.; Hadt, R. G.; Zheng, S.-L.; Chen, Y.-S.; Nocera, D. G. Trap-Free Halogen Photoelimination from Mononuclear Ni(III) Complexes. J. Am. Chem. Soc. 2015, 137 (20), 6472-6475. https://doi.org/10.1021/jacs.5b03192.

(47) Kleverlaan, C. J.; Stufkens, D. J.; Clark, I. P.; George, M. W.; Turner, J. J.; Martino, D. M.; van Willigen, H.; Vlček, A. Photoinduced Radical Formation from the Complexes $\left[\operatorname{Re}(\mathrm{R})(\mathrm{CO})_{3}\left(4,4^{\prime}-\mathrm{Me}_{2}\right.\right.$-bpy $\left.)\right]\left(\mathrm{R}=\mathrm{CH}_{3}, \mathrm{CD}_{3}, \mathrm{Et},{ }^{i} \mathrm{Pr}, \mathrm{Bz}\right)$ : A Nanosecond Time-Resolved Emission, UV-Vis and IR Absorption, and FT-EPR Study. J. Am. Chem. Soc. 1998, 120 (42), 10871-10879. https://doi.org/10.1021/ja980540k.

(48) Rossenaar, B. D.; Kleverlaan, C. J.; Van De Ven, M. C. E.; Stufkens, D. J.; Vlček Jr, A. Mechanism of an Alkyl-Dependent Photochemical Homolysis of the Re-Alkyl Bond in $\left[\operatorname{Re}(\mathrm{R})(\mathrm{CO})_{3}(\alpha\right.$-diimine $\left.)\right]$ Complexes via a Reactive $\sigma \pi^{*}$ Excited State. Chem. - Eur. J. 1996, 2(2), 228-237. https://doi.org/10.1002/chem.19960020216.

(49) Richards, W. G. Spin-Orbit Coupling in Molecules; Trivedi, H. P., Cooper, D. L., Series Eds.; International series of monographs on chemistry; Oxford [England]: Clarendon Press, 1981.

(50) Harvey, J. N. Understanding the Kinetics of Spin-Forbidden Chemical Reactions. Phys. Chem. Chem. Phys. 2007, 9 (3), 331-343. https://doi.org/10.1039/B614390C.

(51) Harvey, J. N. Spin-Forbidden Reactions: Computational Insight into Mechanisms and Kinetics. WIREs Comput. Mol. Sci. 2014, 4 (1), 1-14. https://doi.org/10.1002/wcms.1154.

(52) Penfold, T. J.; Gindensperger, E.; Daniel, C.; Marian, C. M. Spin-Vibronic Mechanism for Intersystem Crossing. Chem. Rev. 2018, 118 (15), 6975-7025. https://doi.org/10.1021/acs.chemrev.7b00617.

(53) Wang, R.-P.; Liu, B.; Green, R. J.; Delgado-Jaime, M. U.; Ghiasi, M.; Schmitt, T.; van Schooneveld, M. M.; de Groot, F. M. F. Charge-Transfer Analysis of 2p3d Resonant Inelastic X-Ray Scattering of Cobalt Sulfide and Halides. J. Phys. Chem. C 2017, 121 (45), 24919-24928. https://doi.org/10.1021/acs.jpcc.7b06882.

(54) Al Samarai, M.; Hahn, A. W.; Beheshti Askari, A.; Cui, Y.-T.; Yamazoe, K.; Miyawaki, J.; Harada, Y.; Rüdiger, O.; DeBeer, S. Elucidation of Structure-Activity Correlations in a Nickel Manganese Oxide Oxygen Evolution Reaction Catalyst by Operando Ni L-Edge XRay Absorption Spectroscopy and 2p3d Resonant Inelastic X-Ray Scattering. ACS Appl. Mater. Interfaces 2019, 11 (42), 38595-38605. https://doi.org/10.1021/acsami.9b06752.

(55) de Groot, F. M. F.; Fuggle, J. C.; Thole, B. T.; Sawatzky, G. A. 2p X-Ray Absorption of 3d Transition-Metal Compounds: An Atomic Multiplet Description Including the Crystal Field. Phys. Rev. B 1990, 42 (9), 5459-5468. https://doi.org/10.1103/PhysRevB.42.5459.

(56) Van Kuiken, B. E.; Hahn, A. W.; Maganas, D.; DeBeer, S. Measuring Spin-Allowed and Spin-Forbidden d-d Excitations in Vanadium Complexes with 2p3d Resonant Inelastic XRay Scattering. Inorg. Chem. 2016, 55 (21), 11497-11501. https://doi.org/10.1021/acs.inorgchem.6b02053.

(57) Hahn, A. W.; Van Kuiken, B. E.; Chilkuri, V. G.; Levin, N.; Bill, E.; Weyhermüller, T.; Nicolaou, A.; Miyawaki, J.; Harada, Y.; DeBeer, S. Probing the Valence Electronic Structure of Low-Spin Ferrous and Ferric Complexes Using 2p3d Resonant Inelastic X-Ray 
Scattering (RIXS). Inorg. Chem. 2018, $57 \quad$ (15), 9515-9530. https://doi.org/10.1021/acs.inorgchem.8b01550.

Hahn, A. W.; Van Kuiken, B. E.; al Samarai, M.; Atanasov, M.; Weyhermüller, T.; Cui, Y.T.; Miyawaki, J.; Harada, Y.; Nicolaou, A.; DeBeer, S. Measurement of the Ligand Field Spectra of Ferrous and Ferric Iron Chlorides Using 2p3d RIXS. Inorg. Chem. 2017, 56 (14), 8203-8211. https://doi.org/10.1021/acs.inorgchem.7b00940.

(59) Gisbertz, S.; Reischauer, S.; Pieber, B. Overcoming Limitations in Dual Photoredox/NickelCatalysed C-N Cross-Couplings Due to Catalyst Deactivation. Nat. Catal. 2020, 3 (8), 611620. https://doi.org/10.1038/s41929-020-0473-6.

(60) Rossenaar, B. D.; Kleverlaan, C. J.; Stufkens, D. J.; Oskam, A. Photochemistry of $\operatorname{ReR}(\mathrm{CO})_{3}\left(\mathrm{Pr}^{i}-\mathrm{Dab}\right)(\mathrm{R}=\mathrm{Me}, \mathrm{Et}, \mathrm{Bn} ; \mathrm{Dab}=1,4-\mathrm{Diazabuta}-1,3-\mathrm{Diene})$ : Homolysis of the $\mathrm{Re}-\mathrm{R}$ Bond, Its Dependence on $\mathrm{R}$ and Evidence for the Reactive $\sigma_{\mathrm{b}} \pi^{*}$ State from Transient Absorption Spectra. J. Chem. Soc. Chem. Commun. 1994, No. 1, 63-64. https://doi.org/10.1039/C39940000063.

(61) Stufkens, D. J.; Vlček, A. Ligand-Dependent Excited State Behaviour of Re(I) and Ru(II) Carbonyl-Diimine Complexes. Coord. Chem. Rev. 1998, 177 (1), 127-179. https://doi.org/10.1016/S0010-8545(98)00132-5.

(62) A. Weinstein, J.; van Slageren, J.; J.Stufkens, D.; Záliš, S.; W. George, M. A TimeResolved Infrared Spectroscopic Study of $\left[\mathrm{M}\left(\mathrm{SnR}_{3}\right)_{2}(\mathrm{CO})_{2}(\alpha\right.$-Diimine $\left.)\right](\mathrm{M}=\mathrm{Ru}, \mathrm{Os} ; \mathrm{R}=$ $\mathrm{Ph}, \mathrm{Me}$ ): Evidence of Charge Redistribution in the Lowest-Excited State. J. Chem. Soc. Dalton Trans. 2001, 18, 2587-2592. https://doi.org/10.1039/B102450G.

(63) Stufkens, D. J.; Aarnts, M. P.; Rossenaar, B. D.; Vlcek, A. A new series of Re- and Rucomplexes having a lowest $\sigma \pi^{*}$ excited state that varies from reactive to stable and long lived. Pure Appl. Chem. 1997, 69 (4), 831-836. https://doi.org/10.1351/pac199769040831.

(64) Aarnts, M. P.; Wilms, M. P.; Stufkens, D. J.; Baerends, E. J.; Vlček, A. $\sigma-\pi^{*}$ Electronic Transition of the Di- and Trinuclear Complexes $\mathrm{Ru}(\mathrm{E})\left(\mathrm{E}^{\prime}\right)(\mathrm{CO})_{2}\left({ }^{(} \mathrm{Pr}-\mathrm{DAB}\right)$ : Resonance Raman, Electronic Absorption, Emission, and Density Functional Study $\left(\mathrm{E}=\mathrm{Me}, \mathrm{SnPh}_{3}\right.$, $\mathrm{M}(\mathrm{CO})_{5} ; \mathrm{E}^{\prime}=\mathrm{M}(\mathrm{CO})_{5} ; \mathrm{M}=\mathrm{Mn}, \mathrm{Re} ;{ }^{i} \operatorname{Pr}-\mathrm{DAB}=\mathrm{N}, \mathrm{N}^{\prime}$-Diisopropyl-1,4-Diaza-1,3Butadiene). Organometallics 1997, $16 \quad$ (10), 2055-2062. https://doi.org/10.1021/om9608667.

(65) Nieuwenhuis, H. A.; van de Ven, M. C. E.; Stufkens, D. J.; Oskam, A.; Goubitz, K. Photochemistry of $\left[\mathrm{Ru}(\mathrm{I})\left({ }^{i} \operatorname{Pr}\right)(\mathrm{CO})_{2}\left({ }^{i} \mathrm{Pr}-\mathrm{DAB}\right)\right]\left({ }^{i} \mathrm{Pr}-\mathrm{DAB}=\mathrm{N}, \mathrm{N}\right.$ '-Diisopropyl-1,4-Diaza1,3-Butadiene): Homolysis of the Metal-Alkyl Bond from the $\sigma_{b}\left(\mathrm{Ru}-{ }^{i} \mathrm{Pr}\right) \pi^{*}$ State. Crystal Structure of the Photoproduct $\left[\mathrm{Ru}(\mathrm{I})_{2}(\mathrm{CO})_{2}\left({ }^{i} \mathrm{Pr}-\mathrm{DAB}\right)\right]$. Organometallics 1995, 14 (2), 780 788. https://doi.org/10.1021/om00002a027.

(66) Rossenaar, B. D.; George, M. W.; Johnson, F. P. A.; Stufkens, D. J.; Turner, J. J.; Vlcek, A. First Direct Structural Information on a Reactive $\sigma \pi^{*}$ Excited State: Time-Resolved UV-Vis and IR Spectroscopic Study of $\operatorname{Re}($ Benzyl $)(\mathrm{CO})_{3}\left({ }^{(} \operatorname{Pr}-\mathrm{DAB}\right)$. J. Am. Chem. Soc. 1995, 117 (46), 11582-11583. https://doi.org/10.1021/ja00151a025.

(67) Vlček, A.; Víchová, J.; Hartl, F. Bond Activation by MLCT Excitation of Organometallic Compounds: Prompt CO-Photodissociation from $\left[\mathrm{Cr}(\mathrm{CO})_{4}\right.$ bpy]. Coord. Chem. Rev. 1994, 132, 167-174. https://doi.org/10.1016/0010-8545(94)80037-5. 